\title{
Coparentalitat i custòdia compartida a Catalunya
}

\author{
Montse Solsona \\ Universitat Autònoma de Barcelona. Departament de Geografia i Centre d'Estudis \\ Demogràfics \\ msolsona@ced.uab.cat \\ Cristina Brullet \\ Institut d'Infancia i Món Urbà i Universitat Autònoma de Barcelona \\ cristina.brullet@uab.cat \\ Jeroen Spijker \\ University of Edinburgh i Centre d'Estudis Demogràfics \\ jspijker@ced.uab.cat
}

\section{Resum}

L'article aborda la problemàtica de la custòdia compartida legal dels fills menors d'edat en el postdivorci dins d'un context de creixent diversitat de les pràctiques parentals. S'hi presenta el marc sociojurídic actual existent a Espanya i a Catalunya entorn de la figura jurídica i la pràctica de la custòdia compartida. A més, s'hi analitzen les dades de sentències judicials de nul-litats, separacions i divorcis en referència al període 2007-2012 procedents de l'INE sobre Catalunya i uns altres territoris de l'Estat espanyol. En els resultats, hi destaca l'especificitat de Catalunya en el context de l'Estat espanyol, amb nivells més alts de divorci, consens entre els cònjuges i custòdia compartida. Concloem que el formidable increment de la custòdia compartida es podria explicar per l'adaptació de la pràctica judicial a nous models de coparentalitat en el predivorci. S'hi planteja la necessitat d'avançar en la recerca qualitativa per conèixer l'impacte real de la custòdia compartida en la vida quotidiana dels nens i els seus progenitors, perquè interpretem que, en la pràctica, aquesta figura jurídica conté i amaga acords ben diversos i crea escenaris molt complexos en el postdivorci.

Paraules clau: divorci; coparentalitat; custòdia compartida; gènere; infancia.

\section{Resumen. Coparentalidad y custodia compartida en Cataluña}

El artículo aborda la problemática de la custodia compartida legal de los hijos menores de edad después del divorcio en un contexto de creciente diversidad de las prácticas parentales. 
Se presenta el marco sociojurídico actual existente en España y en Cataluña en torno a la figura jurídica y a la práctica de la custodia compartida. Además, se analizan los datos de sentencias judiciales de nulidades, separaciones y divorcios en el periodo 2007-2012 procedentes del INE en Cataluña y otros territorios del Estado español. Los resultados destacan la especificidad de Cataluña en el contexto del Estado español, con niveles más altos de divorcio, de consenso entre los cónyuges y de custodia compartida. Concluimos que el formidable incremento de la custodia compartida podría ser el resultado de la adaptación de la práctica judicial a nuevos modelos de coparentalidad en el predivorcio. Se plantea la necesidad de avanzar en la investigación cualitativa para conocer el impacto real de la custodia compartida en la vida cotidiana de los niños y sus progenitores, ya que interpretamos que, en la práctica, esta figura jurídica contiene y esconde acuerdos muy diversos y crea escenarios muy complejos en el postdivorcio.

Palabras clave: divorcio; coparentalidad; custodia compartida; género; infancia.

\section{Résumé. Coparentalité et garde partagée en Catalogne}

Le document aborde la question de la garde partagée des enfants mineurs après le divorce dans un contexte de diversité croissante des pratiques parentales. Nous présentons le cadre socio-juridique qui existe actuellement en Espagne et en Catalogne autour de la figure juridique et la pratique de la garde partagée. Des données judiciaires obtenus par l'INE sur "Décrets d'annulations, séparations et divorces " sont analysés pour la Catalogne et d'autres régions d'Espagne (2007-2012). Les résultats soulignent ce qui est spécifié en Catalogne, dans le cadre de l'État espagnol, avec des niveaux plus élevés de divorce, consensus entre les conjoints et garde partagée. Nous concluons que l'augmentation de la garde partagée peut être le résultat de l'adaptation de la pratique juridique à nouveaux modèles de coparentalité avant le divorce. Cela soulève la nécessité d'étendre la recherche qualitative pour étudier l'impact réel de la garde partagée sur la vie quotidienne des enfants et de leurs parents, que nous interprétons, et que les accords de garde partagée contiennent des situations diverses et complexes qui sont créées après le divorce.

Mots-clés: divorce; coparentalité; garde partagée; genre; enfance.

\section{Abstract. Co-parenting and shared custody in Catalonia}

The paper addresses the issue of legal custody of minor children after divorce in a context of increasing diversity of parental practices. We present a socio-legal framework that currently exists in Spain and Catalonia around the legal entity and practice of shared custody. Judiciary data obtained from INE on "Decrees of annulments, separations and divorces" are analyzed for Catalonia and other Spanish regions (2007-2012). The results highlight the uniqueness of Catalonia in the context of the Spanish State with the highest levels of divorce, fewer disputed judgements and higher rates of shared custody. We conclude that the sharp increase in shared custody could be due to the adaptation of the judicial practices to new models of co-parenting before divorce. This raises the need for qualitative research to study the real impact of shared custody on the daily lives of children and their parents, as we construe that shared custody agreements contain diverse and complex situations that are created after divorce.

Keywords: divorce; co-parenting; shared custody; gender; childhood. 


\section{Sumari}

1. Introducció: el debat ètic i jurídic i les pràctiques parentals

2. Conceptes i evidències jurídiques en relació amb la custòdia compartida

3. La custòdia compartida a Catalunya. Evidències empíriques

4. Reflexions finals
Referències bibliogràfiques

Annex A. Tipus de custòdia segons les característiques dels cònjuges, la unió i el procés legal (Catalunya 2007-2010)

Annex B. Característiques dels cònjuges, la unió i el procés legal segons el tipus de custòdia (Catalunya 2007-2010)

\section{Introducció: el debat ètic i jurídic i les pràctiques parentals}

A Catalunya, en els darrers quinze anys, s'ha avançat en la recerca científica del camp familiar, però encara som lluny d'assolir un coneixement aprofundit dels canvis i les transformacions en les vides quotidianes, i sobretot sabem molt poc de l'experiència viscuda per part dels infants en aquests processos. En el present article, fem una anàlisi dels dictàmens sobre les custòdies de les criatures, bàsica per abordar posteriorment l'experiència dels fills i de les filles menors d'edat en el postdivorci.

La custòdia compartida a Espanya va tenir la primera formulació jurídica l'any 2005, però no serà fins al 2007 que l'Institut Nacional d'Estadística (INE) en publica les primeres dades, on queda palesa l'especificitat de Catalunya en el context de l'Estat espanyol, amb nivells més alts de custòdia compartida. Aquest article pretén aportar algunes respostes explicatives d'aquest fenomen diferencial, amb dos objectius principals. Primer, mostrar el marc jurídic i sociològic de la custòdia compartida a Espanya i a Catalunya, així com dades sobre les pràctiques parentals emergents a Catalunya, objectiu que es cobreix en aquest primer apartat i en el següent. Segon, aportar evidències empíriques sobre l'evolució a Catalunya dels acords de custòdia de fills i filles menors d'edat, a partir de les sentències judicials de ruptures matrimonials referents al període 2007-2012, objectiu que es resol a la tercera part del text.

\subsection{Aspectes politics $i$ legals}

$\mathrm{Al}$ primer decenni del segle xxI, les relacions d'intimitat entre sexes i entre generacions a les societats occidentals mostren profundes transformacions. A Espanya, i especialment a Catalunya, els canvis s'han accelerat i s'han intensificat en els darrers trenta anys durant el procés de construcció d'un sistema democràtic que ha suposat un increment molt notable de la individualització de drets i llibertats, de desenvolupament econòmic i d'inserció creixent de les dones al mercat laboral. Catalunya participa del marc estatal, però presenta especificitats pròpies d'arrel històrica (socials, econòmiques, polítiques, culturals i legislatives) que cal tenir presents en l'anàlisi i en la interpretació del nostre objecte d'estudi. 
Els canvis en les pràctiques familiars s'han estès de manera que va quedant enrere el patró de família moderna de tall patriarcal construït al llarg dels segles XIX i Xx. Les mutacions es manifesten en tres grans dimensions del sistema: a) les legalitats i legitimitats; $b$ ) la divisió sexual del treball de cura familiar i remunerat, $\mathrm{i} c$ ) les relacions de poder entre sexes i entre generacions (Brullet, 2007, 2010). Al nostre entendre, la problemàtica de la custòdia dels fills i filles després d'una ruptura de parella es troba en la cruilla d'aquestes transformacions: legalitats; usos dels temps laborals i de cura, i relacions de poder entre dones i homes.

El creixent procés d'individualització de drets i llibertats que caracteritza les societats occidentals democràtiques avançades planteja el repte de com es pot mantenir i reforçar l'articulació entre individuació i vincle social, entre drets individuals i responsabilitats col-lectives (Molénat, 2006; Beck i Beck-Gernsheim, 2003). La nova figura jurídica de la custòdia compartida es pot considerar un element nou de regulació de les transicions familiars després d'una ruptura d'unió, per tal de fer compatibles els drets i les llibertats individuals dels cònjuges i les seves responsabilitats parentals davant dels fills menors d'edat.

La ruptura legal del vincle matrimonial a Espanya i a Catalunya va ser possible amb la primera Llei de divorci (L 30/1981) de l'Espanya postfranquista (hi hagué Llei de divorci a la II República entre 1931 i 1939). Vint-i-cinc anys després, va ser modificada amb la Llei 15/2005, que va incorporar la figura legal de la custòdia compartida al costat de la custòdia individual. Tanmateix, la custòdia compartida ja era una opció possible en la sentència judicial quan hi havia acord entre les parts. Pel que fa a Catalunya, que disposa de competències legislatives pròpies en dret de família, l'1 de gener del 2011 va entrar en vigor una norma específica ${ }^{1}$ que regula la cura dels fills i de les filles en la postruptura.

\subsection{Evidències sociològiques de les pràctiques parentals a Catalunya}

Cal situar les noves tendències de cura parental en el postdivorci en el marc de les tendències actuals de repartiment de la cura i l'educació de les criatures a les llars biparentals. La recerca realitzada a Catalunya en els darrers quinze anys mostra que, en les famílies joves, la criança compartida a la vida diària guanya terreny lentament a la modalitat convencional en què la mare és la cuidadora quasi en exclusiva. D'un seguit de recerques d'abans de 2008 per diferents àmbits territorials de Catalunya, se'n desprèn que, entre tres i quatre de cada deu llars amb fills menors de diverses edats, el pare i la mare comparteixen la cura de les criatures, encara que no pas de manera simètrica pel que fa als temps de dedicació i el repartiment de les activitats (Brullet, 1996, 1998; Brullet i Roca, 2008; Marí-Klose et al., 2008). En general, la mare hi dedica

1. Llei 25/2010, del 29 de juliol, del Llibre II del Codi Civil de Catalunya, sobre la persona i la família. No s'hi fa un ús explícit del concepte de custòdia compartida, però s'hi afirma el principi de coresponsabilitat parental, que en seria l'expressió pràctica després d'una ruptura conjugal. 
més temps i assumeix més càrrega de cura domèstica i educativa, malgrat que la seva inserció en el mercat laboral tendeixi a ser equivalent en hores a la del pare.

Una estimació més recent per al conjunt de Catalunya a partir de l'Enquesta dels Usos del Temps de 2009-2010 ${ }^{2}$ mostra que el 27,2\% de les llars de parelles amb fills menors de divuit anys, pare i mare compartien, de manera força equitativa, el treball no remunerat (cura de la llar i la família), en tant que cadascú hi contribuïa en un mínim del $40 \%$ del total. I referent a l'any 2012, a Catalunya, tenim que la custòdia compartida es va atorgar en el $26,4 \%$ de les sentències. Entenem que la proximitat dels dos percentatges no és pas casual, sinó que confirma que, a la societat catalana, està emergint a la pràctica un model de criança $i$ cura compartida dels fills que exemplifica les transformacions que es produeixen en les identitats i les relacions de poder en les relacions familiars.

En aquest procés, cal diferenciar la representació ideal d'una coresponsabilitat en la cura familiar al $50 \%$ en la vida quotidiana, de les pràctiques reals i possibles, que sempre mostren una gran variabilitat. Tanmateix, pel que fa a les pràctiques, és lògic considerar-ne els aspectes següents: primer, que, després d'una ruptura d'unió, és molt probable que la custòdia compartida s'adopti de comú acord quan ja hi ha hagut una pràctica prèvia de colllaboració mútua en la cura dels fills en el marc de la vida quotidiana (Solsona i Ferrer, 2010); segon, que els usos dels temps de cura de mares i pares depenen en gran part de les característiques de la jornada de treball remunerat de cadascú i dels patrons laborals dominants (jornades llargues, poca flexibilitat horària, discriminació sexista, etc.), $i$, tercer, que la custòdia compartida portada a bon terme és factible quan les dues parts la volen i la poden organitzar i que no serà viable si un dels dos progenitors no la vol per a si.

Sabem, per la literatura jurídica consultada, que dilucidar aquestes qüestions no sempre és facil (Alascio i Marín, 2007; Sanahuja, 2010; Alascio, 2011; Catalán Frías, 2011; Picontó, 2012), perquè, en una situació de conflicte agut, hi ha en joc molts elements emocionals difícils d'objectivar, a més d'altres interessos de tipus econòmic, patrimonial i residencial. Tanmateix, si, en cas de desacord, la custòdia compartida s'imposa d'acord amb el criteri del jutge, és molt probable que aquesta decisió sigui una font constant de conflicte en el si de la parella anterior i de malestar directe per als fills i les filles.

\subsection{La funció expressiva del dret i el debat sobre l'excepcionalitat i/o la preferència de la custòdia compartida en la norma $i$ en la pràctica jurídiques}

El coneixement sociològic actual sobre les pràctiques parentals ens diu que no és oportú que la norma jurídica consideri la figura de la custòdia compartida com a modalitat "preferent», perquè la pràctica compartida de cura dels fills

2. Agraïm a Marc Ajenjo, del Centre d'Estudis Demogràfics, la seva contribució amb aquesta explotació ad hoc. 
a la vida diària és només una realitat emergent i minoritària, amb grans variacions en el grau de compromís del pare. Tanmateix, vista des de la sociologia i l'antropologia, aquesta nova realitat és molt significativa (tot i ser minoritària), perquè marca futurs possibles a favor d'una cultura més compartida de la cura de les persones en l'àmbit familiar.

En aquest punt, cal fer esment del debat sobre la «funció expressiva del dret» (Sunstein, 1996; Alascio, 2011). Fins on el dret pot i ha de reflectir i/o empènyer les noves tendències i pràctiques socials? Fins a quin punt pot i/o ha de promoure el canvi social? I, sobre la qüestió particular que ens ocupa, fins a quin punt un jutge o una jutgessa pot imposar una custòdia compartida no desitjada per tots dos progenitors, amb la finalitat o la justificació que cal empènyer la coresponsabilitat parental tenint en compte l'interès superior del menor?

En relació amb aquests dilemes, què ha estat succeint en l'aplicació de la llei en casos de divorci conflictiu i manca d'acord entre les parts? Segons la llei estatal de $2005^{3}$, el jutge o la jutgessa, en cas que no hi hagi acord, només pot sentenciar a favor de la custòdia compartida en situacions excepcionals i sempre que es demostri que és en interès superior del menor. A posteriori, tres autonomies ${ }^{4}$ que també tenen capacitat legislativa sobre les conseqüències del divorci, com és el cas de Catalunya, han establert de manera explícita la custòdia compartida com a modalitat "preferent», amb la qual cosa es passa a considerar la custòdia individual com a «excepcional». És a dir, han invertit els termes de la llei de l'any 2005.

Aquesta inversió del punt de vista inicial en l'estudi jurídic d'un cas és molt important, perquè considerar la custòdia compartida com a "preferent» aboca la pràctica judicial a donar per suposat que, a la majoria de les parelles en situació de ruptura, «els és facil, si volen», practicar la custòdia compartida, i això contradiu les evidències aportades per la recerca sociològica fins al dia d'avui. Des del nostre punt de vista, és molt més oportú, quan no hi ha acord entre les parts, mantenir el criteri d'excepcionalitat de la custòdia compartida, tal com apareix a la llei estatal del 2005.

Segons Alascio (2011: 14) —que analitza diversos casos de sentències conflictives i el recorregut que segueixen per diferents instàncies judicials-, el Tribunal Suprem de l'Estat ha tendit a defensar que el jutge o la jutgessa sempre ha d'especificar de manera clara i raonada els motius de la decisió presa, ja sigui a favor de la custòdia individual, ja sigui a favor de la custòdia compartida, perquè cada realitat familiar és diferent, la qual cosa ens sembla que és el que s'ajusta millor a les realitats quotidianes complexes i variades de les famílies d'avui. Les diverses opcions de custòdia han d'estar obertes: custòdia individual (mare o pare), custòdia compartida (parella parental) o

3. Aquesta Llei del 2005 també legislà el matrimoni entre persones del mateix sexe. En aquest estudi sobre la custòdia compartida, només fem referència a les parelles heterosexuals casades amb fills comuns que segueixen un procés de ruptura legal.

4. Aragó: Llei 2/2010; Comunitat Valenciana: Llei 5/2011, i Navarra: Llei Foral 3/2011. 
d'altres tipus (avis, parents, tuteles legals, etc.), sense prejutjar quina ha de ser «preferent» o «excepcional». El que cal és trencar amb la idea preconcebuda i encara dominant que la curadora principal sempre ha de ser la mare.

\section{Conceptes i evidències jurídiques en relació amb la custòdia compartida $^{5}$}

El concepte jurídic de custòdia compartida neix als EUA (joint custody), a finals de la dècada de $1950^{6}$. A Europa, s'hi estén a partir de finals dels anys setanta, primer a Suècia (1976) i Noruega (1981), i després a Finlàndia (1983), Dinamarca (1986), Alemanya (1997), Holanda (1998) i França (2002) (Graversen, 1986; Savolainen, 1986; Gimeno i Ortí, 2008; Halla, 2009; Spruijt i Duindam, 2009; Escobedo, 2011). A Espanya, com ja hem avançat, aquesta figura legal s'hi estableix l'any 2005. A Catalunya, com veurem, s'hi adopta l'any 2011 sota una formulació específica.

La custòdia compartida permet diferenciar entre la ruptura de la parella conjugal i la ruptura de la parella parental, com va assenyalar la sociòloga francesa Irène Théry al seu esplèndid informe Couple, filiation et parenté aujourd'hui (Théry, 1998) sobre les transformacions familiars i el dret de família a França. La custòdia compartida, quan escau, permet considerar que encara que la mare i el pare ja no visquin junts, cap dels dos no "s'ha separat» del fill o la filla menor d'edat, de manera que dóna resposta a una tendència social emergent: el pare que ha participat de la criança dels fills i vol mantenir-hi un vincle regular de cura i atenció. Tanmateix, Théry també deixa ben clar que l'interès superior de l'infant no sempre es resol amb la custòdia compartida; a vegades, es pot assegurar millor amb una custòdia individual. També assenyala que, a França, la custòdia compartida i la residència alternada dels fills són més freqüents entre les classes mitjanes i professionals, perquè els recursos econòmics condicionen la possibilitat de practicar-les.

\subsection{La custòdia compartida a la Llei estatal del divorci (31/1981, 15/2005) i al Llibre II del Codi Civil de Catalunya (2011)}

L'aprovació de la primera Llei de divorci (31/1981) a l'Espanya democràtica va significar una primera ruptura amb la idea de l'amor per a tota la vida. El pas següent, la Llei 15/2005, suposà l'acceptació que la ruptura d'una parella conjugal pot realitzar-se, sense necessitat d'una «causa» de divorci. I el tercer pas (custòdia compartida a la Llei 15/2005) ha estat entendre que hi pot haver

5. Agraïm a l'advocada Mon Tur de IMBgrup, l'assessorament en els aspectes jurídics d'aquest text

6. El 1957, Carolina del Nord va ser el primer estat dels EUA que va aprovar una legislació que permetia la custòdia compartida dels fills després d'un divorci. La majoria dels altres estats van seguir l'exemple des de final de la dècada de 1970 fins als anys noranta del segle passat, i alguns, com ara California, van implementar la custòdia compartida com a modalitat «preferent» (Folberg, 1991). 
ruptura de la parella conjugal, però mantenir, en relació amb els fills comuns, la parella parental.

La Llei estatal 15/2005, de 8 de juliol, elimina el requisit de separació judicial prèvia a la sol-licitud de divorci. En la ruptura, les relacions personals i econòmiques entre les parts i respecte als fills es decideixen en un conveni regulador. Quan els progenitors proposen la custòdia compartida, és el jutge qui en pondera la procedència amb les cauteles que estimi convenient, demanant l'informe al Ministeri Fiscal, escoltant el menor quan escaigui i valorant tant les al-legacions de les parts com la relació entre elles i amb els seus fills. Així mateix, pot determinar la custòdia compartida contra la voluntat d'un dels progenitors, però sempre sota determinades condicions i de manera excepcional.

Catalunya disposa d'un codi civil propi que respon a la tradició històrica legislativa del seu territori. L'1 de gener de 2011, va entrar en vigor el Llibre II del Codi Civil Català sobre la Persona i la Família ${ }^{7}$, que, entre altres aspectes, regula les conseqüències de la ruptura matrimonial per als menors d'edat.

Cal aclarir, en aquest punt, algunes diferències terminològiques entre la norma estatal i la catalana. A Espanya, el Codi Civil manté la figura i els termes de pàtria potestat conjunta entre pare i mare des dels inicis de la democràcia (Llei estatal 11/1981). El reconeixement a la mare de drets que històricament havien estat assignats només al pare va fer possible l'exercici conjunt de la pàtria potestat després del divorci (Lathrop, 2009). A la Llei estatal 15/2005, s'hi mantenen aquests mateixos termes: la pàtria potestat és la responsabilitat parental compartida que només es perd en cas de privació judicial expressa d'aquesta, ja sigui a un progenitor o a tots dos.

En canvi, al Llibre II del Codi Civil de Catalunya sobre la Persona i la Família no es fa ús de l'expressió pàtria potestat si no la de responsabilitat parental (i per potestat parental) ${ }^{8}$.S'hi afirma que la responsabilitat parental és sempre compartida (també és anomenada coparentalitat i coresponsabilitat), tant en les unions com en les ruptures, siguin matrimonials o de fet (excepte si hi ha privació judicial). Tanmateix, en tot el redactat de la Llei, inclòs el preàmbul, no hi apareix el concepte de custòdia compartida, en una clara intenció d'evitació. Sempre es parla de guarda i de les condicions dels pactes i les sentències sobre la cura dels fills menors. Poques vegades es parla de la guarda individual per part d'un sol progenitor. Algunes veus crítiques interpreten que la norma catalana també aposta de manera implícita per donar "preferència» a la custòdia compartida, tal com ja apareix a les normes autonòmiques a València, Aragó i Navarra. Tanmateix, al nostre entendre, el fet d'eludir les expressions custòdia compartida i preferent indica que la llei del Principat s'obre a considerar

7. Llei 25/2010, de 29 de juliol, del llibre segon del Codi Civil de Catalunya, relatiu a la persona i la família.

8. Les legislacions anglosaxones tampoc no contemplen el concepte de pàtria potestat (Gimeno i Ortí, 2008), en canvi, diferencien entre custòdia compartida física (Joint Physical Custody) i custòdia compartida legal (Joint Legal Custody). Aquesta darrera és l'accepció més pròxima a la de coresponsabilitat parental a Catalunya. Als EUA, també es fa ús de Shared Custody per significar una cooperació al 50\% entre els progenitors (Barea, 2012). 
que cada cas s'ha de resoldre segons les circumstàncies familiars específiques, seguint la tendència del Tribunal Suprem de l'Estat, com hem comentat anteriorment.

\subsection{El Pla de parentalitat a Catalunya}

A l'artícle 233-10, i tal com es diu al preàmbul, la primera novetat de la norma catalana és que tota proposta dels progenitors s'ha d'incorporar al procés judicial en forma de pla de parentalitat, instrument per concretar la manera com tots dos pensen exercir les responsabilitats parentals. Tant si el procés és de mutu acord com si és contenciós, s'encoratja els progenitors a organitzar responsablement la cura dels fills i a acordar els criteris de resolució dels problemes més importants que els afectin. Es facilita la col-laboració entre els advocats de cadascuna de les parts i amb psicòlegs, psiquiatres, educadors i treballadors socials independents. La segona novetat és que s'abandona el principi general segons el qual el trencament de la convivència entre la parella significa automàticament que els fills s'han d'apartar de l'un per encomanar-los individualment a l'altre.

Per tant, s'hi afavoreixen les fórmules de coparentalitat i la pràctica de la mediació, però no s'oblida que les relacions familiars en la nostra societat mantenen encara un alt grau de masclisme. També s'ha tingut en compte que el paper de la mare és qualitativament més necessari per als menors que el del pare quan les dinàmiques de la llar han estat construïdes sobre models tradicionals, tant en la idiosincràsia de Catalunya com en la realitat d'altres cultures que s'han incorporat a la nostra societat. Per aquest motiu, es destaquen com a criteris per determinar la guarda individual la vinculació especial dels fills o les filles amb un dels progenitors, i la dedicació als fills que la mare o el pare hagin tingut abans de la ruptura. En la línia de la Llei catalana 5/2008 del dret de les dones a eradicar la violència masclista, s'exclou de tota participació en la guarda el progenitor contra el qual hi hagi sentència ferma o indicis fonamentats de violència familiar o de gènere.

Finalment, es reconeix el caràcter privilegiat de les relacions dels menors amb l'entorn més proper, amb els avis, les àvies, els germans i les germanes, $\mathrm{i}$ s'estableix un procediment per fer efectiu el dret de les menors i els menors a mantenir aquestes relacions personals.

\subsection{L'atribució de l'ús de l'habitatge familiar i el repartiment de les despeses dels fills i les filles}

La llei espanyola regula que, en el cas de custòdia individual, s'atribueix al progenitor custodi l'habitatge familiar (art. 96 del Codi Civil espanyol) i el dret del menor a la percepció d'una pensió alimentària del progenitor no custodi (art. 93 del Codi Civil espanyol). En cas de custòdia compartida, s'atendrà allò que els cònjuges en via de ruptura estableixin en el conveni regulador. Segons Alascio (2011: 5), però, no es deixa clar com cal procedir 
en cas de desacord, la qual cosa permet barrejar qüestions patrimonials amb relacions personals.

La fórmula catalana estableix que en cas de custòdia compartida, l'atribució de l'habitatge es farà al progenitor més necessitat (art. 233-20), a més de seguir uns altres criteris raonables, la qual cosa pot reduir els conflictes. Cal valorar les circumstàncies de cada cas concret i, a més, l'atribució d'habitatge és sempre temporal, perquè les situacions poden variar.

Respecte a les despeses dels fills i les filles, la regulació en la custòdia compartida és que cada progenitor aboni les despeses ordinàries generades en el seu període de custòdia i que les extraordinàries s'assumeixin per meitats. L'inconvenient és que un dels progenitors esperi que sigui l'altre qui faci la despesa ordinària en roba o en material escolar. Alascio comenta que, pel que respecta a les despeses extraordinàries, segurament convindria distribuir-les segons quina sigui la capacitat econòmica de cada progenitor, i que potser també hauria de ser així en el cas de les ordinàries (Alascio, 2011: 21). Aquesta és la línia que segueix la norma catalana: les despeses dels fills han de ser assumides segons la capacitat econòmica de cada progenitor.

\section{La custòdia compartida a Catalunya. Evidències empíriques}

En aquesta secció, hi presentem els trets característics de la custòdia compartida atorgada en les sentencies de divorci, separacions i nul-litats a Catalunya, que, en el curt període de sis anys, ha passat del l'11\% de 2007 al 26\% de 2012.

\subsection{Fonts de dades i metodologia}

La informació bàsica d'aquest estudi prové del butlletí estadístic que, des de l'any 19969, s'emplena al jutjat i es remet a l'INE cada vegada que es dicta una sentència de divorci, separació o nul.litat.

Cal fer aquí alguns aclariments metodològics. Primer: per analitzar l'evolució i les característiques de la custòdia compartida a Catalunya a partir de les sentències, només tenim informació de les ruptures legals de les unions matrimonials. Per tant, queden fora del nostre objecte d'estudi els matrimonis amb fills que es trenquen però que no segueixen un procés judicial, a més de totes les ruptures de parelles de fet amb fills que, encara que passin pels jutjats de família, no formen part de les estadístiques que confegeix l'INE. Aquestes casuístiques només es podrien captar a partir d'enquestes específiques amb informació sobre les històries de les unions i les ruptures. Segon: les dades de les sentències sobre custòdia compartida només fan referència a les ruptures amb fills menors de 18 anys, sense distinció d'edat (els butlletins estadístics no

9. La Llei de divorci data de 1981, però no és fins al 1996 que s'implementa el butlletí estadístic als jutjats, en virtut d'un acord entre el Consell General del Poder Judicial i l'Institut Nacional d'Estadística d'Espanya. Abans de 1996, només teníem dades publicades a la Memòria Anual del Consell General del Poder Judicial agregades per al conjunt d'Espanya. 
registren aquesta dada), perquè quan hi ha fills més grans, encara que siguin econòmicament dependents, no es dicta sentència respecte a la custòdia. Per tant, la fotografia estadística que oferim aquí a partir de les sentències haurà de ser completada en el futur amb recerques ad hoc que recullin les ruptures de les unions amb fills en tot l'univers més ampli. Tercer: els butlletins estadístics recullen informació des de 1996 sobre els cònjuges, les característiques de la unió i el procés judicial, però no és fins l'any 2007, després de la reforma de 2005, quan disposem d'informació sobre el tipus de custòdia atorgada, a més de dues variables noves (nacionalitat i sexe dels cònjuges). És per aquesta raó que centrarem l'anàlisi en el període 2007-2012.

Pel que fa als resultats, presentem, en primer lloc, i per al període 20072012, dades sobre Catalunya i l'Estat espanyol — publicades pel propi INE-, i diferents agregats territorials: Catalunya, Espanya, la resta de l'Estat espanyol (sense Catalunya) i comunitats autònomes.

En segon lloc, per a un període més curt (2007-2010), fem una explotació original per al cas català de les microdades que adquirim a l'INE i que abasten, aproximadament, el $70 \%$ de les sentències. Per tal que les xifres quadrin amb el total de sentències dictades, hem aplicat un factor de ponderació proporcionat pel propi INE. En l'anàlisi descriptiva, hi comentarem els trets més destacats de la custòdia compartida en contrast amb els de la custòdia individual (mare o pare), pel que fa a les característiques sociodemogràfiques dels cònjuges, de la unió i del procés legal (que seran les nostres variables explicatives o independents). Algunes de les variables incloses s'obtenen directament dels butlletins (nacionalitat $\mathrm{i}$ altres), mentre que unes altres són derivades (diferència d'edat entre els esposos, durada del matrimoni). Val a dir que, en general, tractem conjuntament les sentències de separacions i de divorci, atès que el pes dels divorcis en els tres tipus de custòdia és el mateix (entorn al 92\%).

Per acabar, completem l'anàlisi descriptiva amb una anàlisi multivariant (regressió logística) que ens permet determinar els factors estadísticament més significatius que incideixen en la custòdia compartida.

\subsection{Catalunya i Espanya: del consens a la custòdia compartida}

Catalunya destaca, a l'Estat espanyol, perquè té nivells elevats de: a) divorcialitat, b) custòdia compartida i c) consens entre els cònjuges en el procés legal. L'elevada inserció de les dones al mercat de treball10 (Caprile et al., 1998; Torns et al., 2007; Generalitat de Catalunya, 2008; Homs i Caprile, 2010), majoritàriament a temps complet; un contracte de gènere que avança — de manera moderada però contínua - cap a una equitat més gran, reflectida,

10. A Catalunya, des de l'any 2000 i fins l'any 2008, la taxa d'ocupació de les dones va augmentar en gairebé un $11 \%$ (del $51,4 \%$ al $62,2 \%$ ), fins a superar els valors espanyol, de la zona euro i europeu $(54,9 \%, 58,8 \%$, i 59,1\%, respectivament) (IDESCAT, 2009). L'any 2010 , l'ocupació va baixar fins al 58,3\% a Catalunya, al 52,3 \% a Espanya i el 58,2\% a la UE-27 (IDESCAT, 2011). 


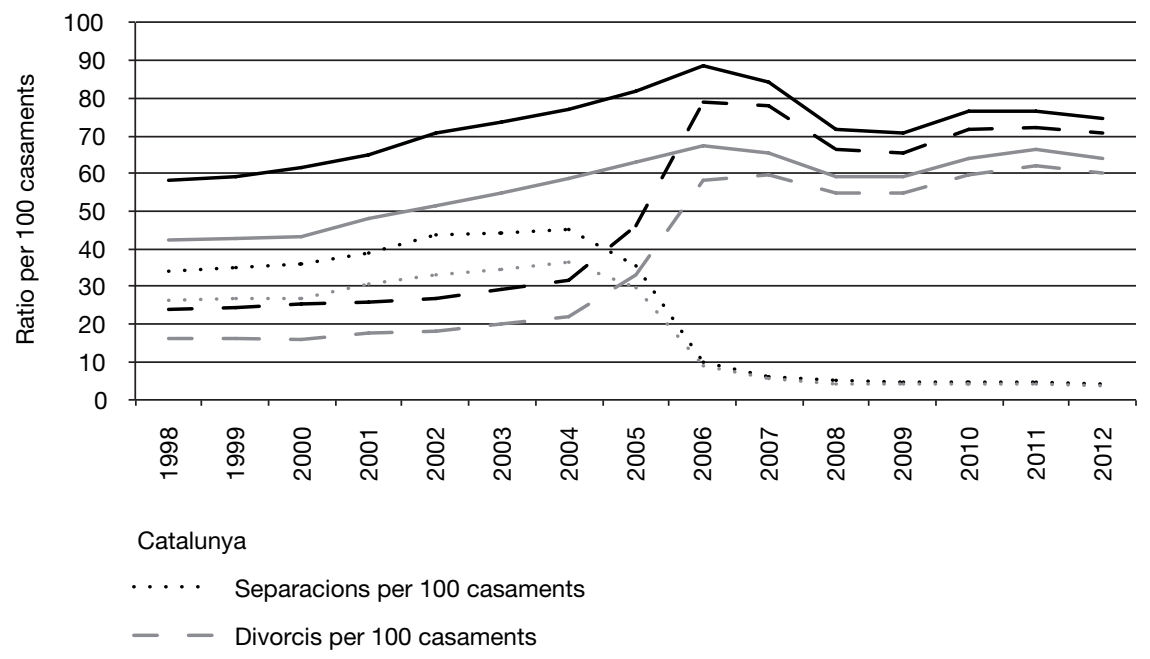

Espanya sense Catalunya

$\begin{array}{ll}\ldots . . . \text { Separacions per } 100 \text { casaments } & -\quad-\text { Divorcis per } 100 \text { casaments } \\ & \text { Ruptures per } 100 \text { casaments }\end{array}$

Figura 1. Separacions i divorcis per 100 casaments. Catalunya i la resta de l'Estat espanyol (1998-2012)

Font: www.ine.es i elaboració pròpia.

entre altres indicadors, en els percentatges més elevats de pràctiques de cura compartida (treball familiar) de les parelles amb fills (Brullet, 1996, 1998; Torns et al., 2008; Institut d'Estadística de Catalunya, 2007, 2011; Brullet i Roca, 2008; Moreno, 2013); un marc legislatiu respectuós amb els drets i deures dels pares i les mares (Llei 25/2010, del 29 de juliol, del Llibre II del Codi Civil de Catalunya, sobre la persona i la família), i una certa tradició cultural pactista (Dowling, 2013) són factors que afavoreixen, sens dubte, els valors elevats d'aquests indicadors.

a) L'alta divorcialitat a Catalunya queda il.lustrada a la figura 1, on es pot veure que les corbes de les separacions i dels divorcis per cent casaments van per sobre de les de la resta de l'Estat ${ }^{11}$, excepte en el darrer tram de les separacions, perquè aquestes ja són molt residuals per efecte de la reforma de 2005, quan la separació deixa de ser un tràmit obligatori i es produeix de

11. La necessitat de comparar l'evolució de Catalunya no amb la totalitat de l'Estat, sinó amb la resta d'Espanya, es justifica perquè, si comparéssim Catalunya amb Espanya (dins la qual hi hauria Catalunya), no podríem apreciar completament la singularitat del cas català, atès que el pes del Principat a la mitjana espanyola és molt important. 
Taula 1. Xifres expressades en tants per cent sobre les ruptures de matrimonis segons la custòdia atorgada (Catalunya i la resta de l'Estat espanyol 2007-2012)

\begin{tabular}{lrrrrrr}
\hline \multicolumn{7}{c}{ Catalunya } \\
Custòdia & 2007 & 2008 & 2009 & 2010 & 2011 & \multicolumn{2}{c}{2012} \\
\hline Mare & 83,2 & 82,2 & 79,6 & 77,7 & 73,2 & 61,8 \\
Pare & 5,0 & 4,4 & 5,9 & 5,0 & 5,3 & 10,9 \\
Tots dos & 11,7 & 13,1 & 14,0 & 16,5 & 20,6 & 26,4 \\
Altres & 0,1 & 0,3 & 0,5 & 0,7 & 0,9 & 0,9 \\
\hline \multicolumn{7}{c}{ Espanya sense Catalunya } \\
Custòdia & 2007 & 2008 & 2009 & 2010 & 2011 & 2012 \\
\hline Mare & 86,0 & 86,8 & 85,0 & 84,5 & 83,5 & 78,0 \\
Pare & 4,7 & 4,0 & 5,5 & 5,8 & 5,3 & 9,5 \\
Tots dos & 9,3 & 8,9 & 8,7 & 9,0 & 10,5 & 12,0 \\
Altres & 0,1 & 0,3 & 0,7 & 0,6 & 0,7 & 0,5 \\
\hline
\end{tabular}

Font: www.ine.es i elaboració pròpia.

forma simultània un creixement (i una concentració els dos anys següents) dels divorcis. A Espanya, el divorci segueix sent socialment selectiu, atès que es relaciona amb la cúspide de la piràmide social i s'associa positivament a nivells d'instrucció elevats i a l'activitat laboral de les dones, dues raons que expliquen la divorcialitat més elevada de Catalunya (Solsona i Simó, 2007).

b) La custòdia compartida a Catalunya és molt més elevada l'any 2012 que a la resta de l'Estat espanyol (26,4\% i 12,0\%, respectivament), mentre que l'any 2007 els valors eren força semblants. Després, Catalunya inicia una tendència creixent a expenses de la custòdia individual de la mare, mentre que la resta de l'Estat no experimenta canvis aparents fins al 2012 (taula 1). No hi ha diferències entre tots dos territoris pel que fa al pes de la custòdia atribuïda solament al pare fins l'any 2011 (entorn del 5,5\%), però, entre 2011 i 2012, pràcticament es dobla en tots dos casos. La custòdia atorgada a unes altres persones, molt minoritària, no assoleix l'1\% en cap moment, tot i que manté una tendència creixent. La xifra del $26,4 \%$ de custòdia compartida a Catalunya referent a l'any 2012 és certament propera al pes de les parelles amb fills menors de 18 anys que comparteixen en gran mesura el treball no remunerat $(27,2 \%)$, com vam apuntar anteriorment.

La situació a la resta de l'Estat espanyol inclou situacions dispars entre comunitats autònomes. Les Balears, València ${ }^{12}$ i Aragó comparteixen amb Catalunya una freqüència elevada $i$ una tendència notable creixent de custòdies compartides (figura $2 \mathrm{i}$ taula 2), segurament en part per les iniciatives legislatives promogudes en aquestes comunitats, a les quals ja hem fet referència.

12. Sobre dades relatives a les transformacions familiars als Països Catalans en el marc de l'Estat espanyol, podeu consultar Cardús (1999) i Brullet (2008). 


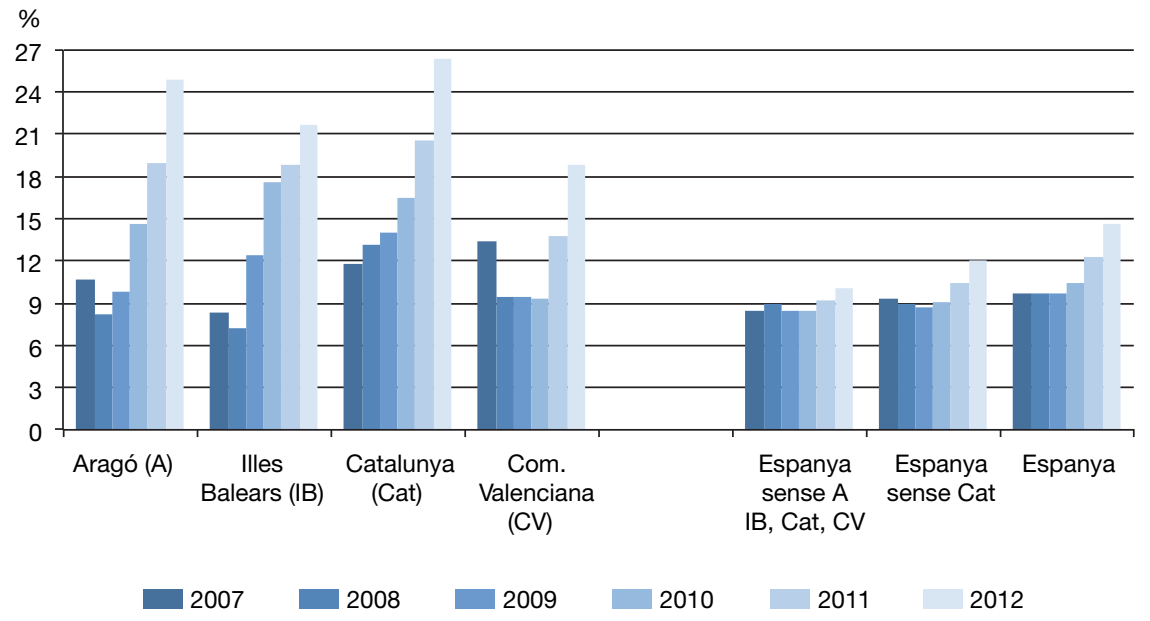

Figura 2. Custòdia compartida als Països Catalans, a l'Aragó i a la resta de l'Estat espanyol (2007-2012)

Font: www.ine.es i elaboració pròpia.

Taula 2. Sentències consensuades i custòdia compartida (en tants per cent). Comunitats autònomes (2007-2012)

\begin{tabular}{|c|c|c|c|c|c|c|}
\hline \multirow[b]{2}{*}{ CCAA } & \multicolumn{4}{|c|}{$\%$ sentències consensuades } & \multicolumn{2}{|c|}{ \% custòdia compartida } \\
\hline & 1999 & 2003 & 2007 & 2012 & 2007 & 2012 \\
\hline Andalusia & 49,5 & 57,4 & 55,4 & 58,2 & 9,7 & 6,9 \\
\hline Aragó & 69,1 & 72,8 & 69,8 & 71,8 & 10,6 & 24,9 \\
\hline Astúries & 51,3 & 63,6 & 62,6 & 67,3 & 14,4 & 12,2 \\
\hline Balears (IIles) & 63,1 & 70,1 & 67,1 & 71,2 & 8,3 & 21,6 \\
\hline Canàries & 51,7 & 59,3 & 54,1 & 59,5 & 7,1 & 12,4 \\
\hline Cantàbria & 48,6 & 64,7 & 66,2 & 69,6 & 4,7 & 9,9 \\
\hline Castella i Lleó & 52,4 & 61,1 & 57,9 & 67,0 & 11,7 & 9,8 \\
\hline Castella-la Manxa & 51,5 & 61,7 & 61,1 & 63,0 & 9,9 & 9,0 \\
\hline Catalunya & 65,1 & 75,9 & 71,2 & 72,9 & 11,7 & 26,4 \\
\hline País Valencià & 61,6 & 68,9 & 67,4 & 67,2 & 13,4 & 18,8 \\
\hline Extremadura & 44,2 & 55,9 & 57,0 & 64,8 & 5,7 & 8,2 \\
\hline Galícia & 48,5 & 59,1 & 54,5 & 64,5 & 8,1 & 9,9 \\
\hline Madrid & 61,0 & 68,7 & 64,9 & 67,9 & 6,3 & 12,6 \\
\hline Múrcia & 56,7 & 62,8 & 56,9 & 62,6 & 8,2 & 5,9 \\
\hline Navarra & 75,8 & 78,3 & 72,9 & 73,5 & 6,7 & 12,5 \\
\hline País Basc & 65,4 & 69,2 & 67,7 & 70,9 & 8,4 & 14,5 \\
\hline Rioja (La) & 60,0 & 70,6 & 68,4 & 68,2 & 12,2 & 13,2 \\
\hline Espanya & 58,0 & 66,3 & 63,0 & 66,1 & 9,7 & 14,6 \\
\hline
\end{tabular}

Font: www.ine.es. 


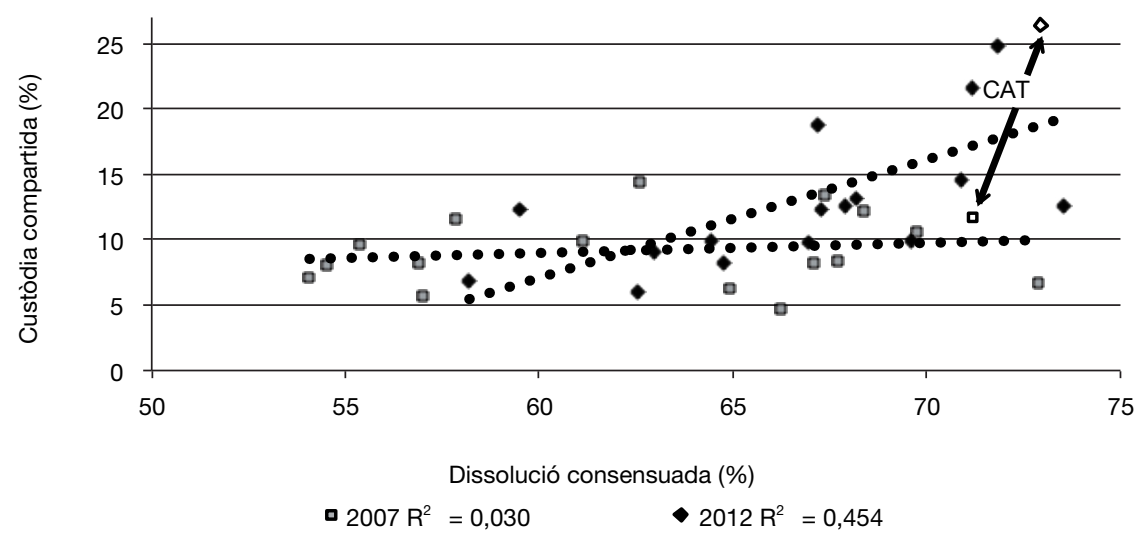

Figura 3. Correlació entre la ruptura (separació o divorci) amb sentència consensuada i custòdia compartida (comunitats autònomes 2007 i 2012)

Font: www.ine.es.

Nota: els punts representen les 17 comunitats autònomes.

c) Podem associar positivament la custòdia compartida amb el consens entre els cònjuges i la seva capacitat per arribar a acords, però també a una nova cultura i pràctica jurídiques ${ }^{13}$ més compromeses amb el respecte als drets i els deures de les dues parts i que, presumiblement, tenen més en compte l'experiència de cura familiar abans de la ruptura, almenys en el cas català.

En comparar la importància de les sentències consensuades amb la de la custòdia compartida per comunitats autònomes, en un moment determinat en el temps, observem que, l'any 2007, no hi ha relació entre totes dues variables, bàsicament, perquè, amb independència del nivell de consens, el pes de la custòdia compartida és molt baix a totes les comunitats. En canvi, l'any 2012, la correlació entre totes dues variables és clarament positiva: a més consens, més custòdia compartida (figura 3). Tanmateix, en l'evolució temporal, es pot interpretar el consens com un preludi de la custòdia compartida, atès que les quatre comunitats autònomes (Catalunya, País Valencià, Aragó i les Illes Balears) que registren els nivells més elevats de custòdia compartida l'any 2012 (i també de sentències consensuades) es caracteritzen perquè registren uns nivells de consens superiors a la mitjana espanyola molt abans de la reforma de 2005 (taula 2). Ara bé, Navarra és un cas especial. Malgrat que disposa d'una legislació pròpia que dóna preferència a la custòdia compartida i que, des de 1999, mostra una tendència pronunciada a les ruptures consensuades (entorn del 75\%), presenta, en canvi, un percentatge

13. Catalunya, a banda de disposar d'una legislació pròpia, acull l'Escola de Formació Judicial de l'Estat espanyol, on es centralitzen les activitats de formació judicial de caràcter internacional i també d'igualtat. 
molt baix de custòdies compartides, almenys en referència a l'últim any sobre el qual hi ha dades disponibles (un 12,5\%). Aquesta excepcionalitat respon, probablement, al petit nombre de dictàmens anuals que s'emeten (uns 650), la qual cosa provoca una tendència temporal molt irregular (el 2008, un 21,3\% de les sentències va ser de custòdia compartida, una de les proporcions més altes).

\subsection{Trets característics de la custòdia compartida a Catalunya (2007-2010)}

A Catalunya, durant el període 2007-2012, més de 127.000 parelles casades van obtenir dels jutjats una sentència de separació o divorci, i poc més de la meitat (67.073) tenien fills menors de 18 anys. Al final del període estudiat, l'any 2012, van passar pels jutjats més de 10.000 parelles amb fills; de les quals, 1 de cada 4 (entorn de 2.800 famílies) va obtenir la custòdia compartida, de manera que aquesta opció va adquirint cada vegada més envergadura (taula 3).

Amb les microdades de què disposem, podem estudiar més a fons un període de quatre anys, entre 2007 i 2010 . En aquest temps, d'un total de 46.026 ruptures matrimonials amb fills menors de 18 anys, en 37.196 casos es va atorgar la custòdia exclusiva a la mare; en 2.330 , al pare, i en 6.330, la custòdia compartida entre el pare $\mathrm{i}$ la mare. A la taula $\mathrm{A} i$ a la taula $\mathrm{B}$ de l'annex, s'hi pot consultar el detall de la distribució (xifres absolutes i relatives) dels diferents tipus de custòdia (compartida, pare, mare), com també de les variables explicatives sobre els cònjuges (edat que tenien quan es van casar i en el moment de la sentència, estat civil anterior, separació prèvia, nacionalitat), sobre la unió (durada, nombre de fills menors de 18 anys, etc.) i sobre el procés legal (data de la demanda i de la sentència, tipus de demanda i tipus de sentència, duració del procés, pensió compensatòria i d'aliments).

En comparació amb la custòdia individual atorgada a la mare, la custòdia compartida s'atribueix amb més freqüència a parelles amb edats una mica més elevades en el moment de casar-se, quan tots dos membres són de nacio-

Taula 3. Custòdia compartida. Ruptures matrimonials amb fills menors de 18 anys (xifres absolutes i relatives) (Catalunya 2007-2012)

\begin{tabular}{lccc}
\hline & $\begin{array}{c}\text { 1. Total } \\
N\end{array}$ & $\begin{array}{c}\text { 2. Amb fills menors } \\
N \text { (com. \% d'1) }\end{array}$ & $\begin{array}{c}\text { 3. Custòdia compartida } \\
N \text { (com. \% de 2) }\end{array}$ \\
\hline 2007 & 25.752 & $13.064(50,7 \%)$ & $1.535(11,7 \%)$ \\
2008 & 21.913 & $11.488(52,4 \%)$ & $1.504(13,1 \%)$ \\
2009 & 19.478 & $10.364(53,2 \%)$ & $1.455(14,0 \%)$ \\
2010 & 20.801 & $11.108(53,4 \%)$ & $1.835(16,5 \%)$ \\
2011 & 19.727 & $10.460(53,0 \%)$ & $2.156(20,6 \%)$ \\
2012 & 19.801 & $10.593(53,5 \%)$ & $2.794(26,4 \%)$ \\
Total & 127.472 & $67.077(52,6 \%)$ & $11.279(16,8 \%)$ \\
\hline
\end{tabular}

Font: www.ine.es i elaboració pròpia. 
nalitat espanyola i quan presenten la demanda de mutu acord. Així mateix, en la custòdia compartida, els processos legals són més curts (el 76,2\% duren menys de sis mesos, enfront del $69,1 \%$ si la mare n'obté l'exclusiva, o només el $53,8 \%$ si és el pare qui l'obté), la qual cosa es relaciona amb un nombre més elevat de sentències consensuades (el 75\% en comparació amb el 65,3\% si l'obté la mare, o només el 51,6\% si l'obté el pare). I, com era d'esperar, en la custòdia compartida, les mares participen en el pagament de les pensions d'aliments (en un 48,5\% dels casos, ho fan tots dos, enfront del 48,6\% que paga el pare, i només un 2,9\% la mare) (taula A de l'annex). El fet que en el $48,6 \%$ dels casos la pagui només el pare, encara que es tracti d'una custòdia compartida, d'entrada, és paradoxal, raó per la qual reprenem aquest tema més avall.

Els dictàmens també contenen informació que ens permet afinar i matisar l'anàlisi anterior (taula B de l'annex). Per exemple, l'efecte positiu d'una edat més madura (35-49 anys) del pare en el moment de casar-se es reforça quan se'n mesura l'edat en el moment en què s'emet la sentència, i quan la duració del matrimoni — que la podem prendre com una variable proxy de l'edat dels fills - és superior a cinc anys. Dit altrament, la propensió a la custòdia compartida és més intensa en parelles amb criatures que no són gaire petites $\mathrm{i}$ que han seguit un recorregut durant el qual el pare i els fills han acumulat una experiència relacional més gran. Aquest factor - tenir fills menors d'edat però ja "grans»— sembla que és més determinant en l'accés a la custòdia compartida que no pas la joventut de les generacions de parelles sobre les quals presumim unes actituds més favorables a la coparentalitat.

Unes altres variables que també s'associen positivament a la custòdia compartida són les unions homogàmiques pel que fa a l'edat, la nacionalitat (espanyola) i l'estat civil anterior de tots dos (no haver estat divorciat). Totes tres condicions poden afavorir un equilibri de poder més gran en el procés de negociació a què abans feiem al.lusió $\mathrm{i}$, tal vegada, una cultura de gènere més propera a la pràctica de la coparentalitat (taula B).

Per últim, l'anàlisi multivariant ${ }^{14}$, que incorpora l'any de la sentència $\mathrm{i}$ que controla l'efecte de les variables que estan relacionades entre si (excloses del model que presentem), proporciona l'efecte net de cada variable, resumeix tots els resultats anteriors i permet afirmar que les variables explicatives més significatives en l'accés a la custòdia compartida són: any del divorci, edat adulta madura del marit, nacionalitat espanyola, presència de dos fills, demanda presentada per tots dos i sentència consensuada. Més amunt, ja hem mostrat que, com més recent és el divorci, més freqüent és la custòdia compartida. Sembla clar que la Llei 25/2010 de Catalunya i la jurisprudèn-

14. El mètode escollit és una regressió logística binomial, tot i tenir una variable dependent (tipus de custòdia) amb tres possibilitats. Tanmateix, la regressió multinomial només esdevindria el mètode adequat si l'objectiu fos comparar les associacions de les característiques de les sentències entre les tres possibilitats (pare, mare, compartida). En canvi, l'objectiu de la nostra anàlisi és obtenir les propensions a la custòdia compartida de les diferents característiques de les sentències. 
cia que s'havia acumulat abans ${ }^{15}$ estan afavorint l'augment de les custòdies compartides.

Als nostres ulls, la demanda de mutu acord i la sentència consensuada, tots dos factors, constitueixen una condició necessària perquè reïxi una custòdia compartida que, a partir de 2011, haurà de disposar d'un pla detallat sobre com s'exercirà la parentalitat. Tal com passa amb la custòdia exclusiva del pare, es fa palesa una actitud més activa per part del progenitor en el procés legal cap a la custòdia compartida, en comparació amb la situació en què s'acaba atorgant la custòdia a la mare. En un estudi anterior sobre la custòdia individual atorgada al pare en el cas d'Espanya (Spijker, 2012), ja s'ha mostrat que els processos legals que l'acaben atorgant són peculiars: més llargs, més conflictius i més difícils de concloure (taula 4).

\subsection{Desigualtats de gènere, pensions i custòdia compartida}

En els processos legals de divorci, s'hi fixen dos tipus de pensions: la compensatòria i la d'aliments. Aquí analitzem les sentències, no pas si es compleixen o no. La pensió compensatòria té per funció corregir les diferències en el nivell de vida de cada excònjuge com a conseqüència de la ruptura, però a la pràctica jurídica és molt poc freqüent (no en tenim informació en el $88 \%$ de les dades analitzades). Tanmateix, en els casos en què s'ha obtingut informació, segons la sentència, l'exmarit hauria de pagar aquesta pensió a l'exmuller, no solament quan ella té la custòdia dels fills, sinó també en el $92 \%$ dels casos de custòdia compartida, i en el $43 \%$ quan ell mateix té la custòdia en exclusiva. Encara que aquesta pensió compensatòria sigui poc freqüent, constitueix un indicador prou clar de les desigualtats econòmiques i de poder que es mantenen en el si del matrimoni.

Pel que fa a la pensió alimentària, gairebé en el 90\% del total d'exemples de divorcis amb fills menors de 18 anys és el pare qui l'hauria de pagar (20072010) (figura 4). Quan la mare tenia la custòdia en exclusiva, la pensió havia de ser pagada pel pare en un $82 \%$ dels casos. En cas de custòdia compartida, el pare havia de pagar-la en el $45 \%$ dels casos, la mare en el 3\%, i en el 52\% l'havien de pagar entre tots dos.

En una situació ideal de simetria en la distribució dels temps de cura i d'accés als recursos materials, la pensió d'aliments hauria de ser pagada entre la mare i el pare, però les sentències ens diuen que només es reparteix la despesa d'aliments en el 52\% de les situacions de custòdia compartida. Ja hem apuntat més amunt que sempre cal diferenciar entre la representació ideal, la sentència judicial i les pràctiques reals. A les sentències judicials, s'hi busquen acords als quals és relativament facil d'arribar quan hi ha situacions de poder (econòmic,

15. La Sentència número 29/2008, de 31 de juliol, del Tribunal Superior de Justícia de Cataluña (que unifica la doctrina en dret civil català) ja es va manifestar a favor de la custòdia compartida dels fills en una sentència de divorci i la va considerar beneficiosa per al fill, per repartir millor les càrregues familiars i per a la transmissió de valors no sexistes. L'argumentació, que també inclou referències internacionals, ha estat i és un antecedent per a jutges d'instàncies inferiors i per a advocats de família. 
Taula 4. Anàlisi de regressió logística multivariant dels factors associats amb la custòdia compartida i la custòdia exclusiva (pare o mare) (Catalunya 2007-2010)

\begin{tabular}{|c|c|c|c|c|c|c|c|c|}
\hline \multirow[b]{3}{*}{ Factor } & \multirow[b]{3}{*}{ Variable } & \multirow[b]{3}{*}{ Categoria } & \multicolumn{6}{|c|}{ Custòdia } \\
\hline & & & \multicolumn{2}{|c|}{ Compartida } & \multicolumn{2}{|c|}{ Mare } & \multicolumn{2}{|c|}{ Pare } \\
\hline & & & Odds & Sig & Odds & Sig & Odds & Sig. \\
\hline \multirow[t]{4}{*}{ Temps } & Any de referència & 2007 & Ref. & & Ref. & & Ref. & \\
\hline & & 2008 & 1,14 & 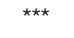 & 0,91 & $\star \star \star \star$ & 0,92 & \\
\hline & & 2009 & 1,20 & $\star \star \star *$ & 0,79 & $\star \star \star$ & 1,20 & $\star \star \star$ \\
\hline & & 2010 & 1,46 & 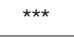 & 0,69 & $\star \star \star \star$ & 1,12 & * \\
\hline \multirow[t]{6}{*}{ Cònjuges } & Edat del pare & $<30$ anys & Ref. & & Ref. & & Ref. & \\
\hline & en el moment & 30-34 anys & 1,13 & & 0,86 & $\star \star \star \star$ & 1,15 & \\
\hline & de la sentència & 35-39 anys & 1,27 & ** & 0,83 & 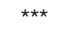 & 0,93 & \\
\hline & & 40-44 anys & 1,32 & 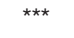 & 0,77 & $\star \star \star \star$ & 1,09 & \\
\hline & & 45-49 anys & 1,35 & $\star \star \star *$ & 0,73 & 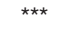 & 1,24 & \\
\hline & & $50+$ anys & 1,41 & $\star \star \star *$ & 0,67 & 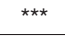 & 1,38 & * \\
\hline \multirow[t]{15}{*}{ Unió } & Diferència & Homogàmia & Ref. & & Ref. & & Ref. & \\
\hline & d'edat entre & Hipogàmia & 0,88 & ** & 1,04 & & 1,24 & $\star \star \star \star$ \\
\hline & els conjuges & Hipergàmia & 0,94 & & 0,98 & & 1,22 & ${ }^{\star \star \star}$ \\
\hline & Nacionalitat & 2 espanyols & Ref. & & Ref. & & Ref. & \\
\hline & dels cònjuges & 1 espanyol i 1 estranger & 0,81 & 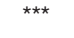 & 1,14 & $\star \star$ & 1,16 & \\
\hline & & 2 estrangers & 0,70 & 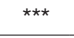 & 1,33 & 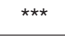 & 0,94 & \\
\hline & Durada del & $<5$ anys & Ref. & & Ref. & & Ref. & \\
\hline & matrimoni & 5-10 anys & 1,12 & * & 0,92 & & 0,91 & \\
\hline & & $10-20$ anys & 0,98 & & 0,93 & & 1,38 & 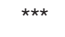 \\
\hline & & $20+$ anys & 0,96 & & 0,86 & 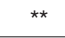 & 1,66 & $\star \star \star *$ \\
\hline & Estat civil & Solter & Ref. & & Ref. & & Ref. & \\
\hline & anterior del marit & Divorciat/vidu & 0,90 & & 1,08 & & 0,96 & \\
\hline & Fills menors & 1 & Ref. & & Ref. & & Ref. & \\
\hline & & 2 & 1,19 & $\star \star \star *$ & 0,93 & 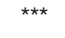 & 0,79 & $* \star \star$ \\
\hline & & $3+$ & 1,11 & & 0,91 & * & 0,85 & * \\
\hline \multirow{10}{*}{$\begin{array}{l}\text { Procés } \\
\text { judicial }\end{array}$} & Demandant & Mare & Ref. & & Ref. & & Ref. & \\
\hline & & Pare & 1,48 & $\star \star \star ~$ & 0,51 & $* * *$ & 2,71 & 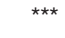 \\
\hline & & Tots dos & 1,57 & $\star \star \star$ & 0,61 & *** & 1,34 & *** \\
\hline & Durada & $<6$ mesos & Ref. & & Ref. & & Ref. & \\
\hline & del procés & 6-11 mesos & 1,03 & & 0,85 & $\star \star \star ~$ & 1,47 & $\star \star \star ~$ \\
\hline & & $12+$ mesos & 1,01 & & 0,85 & $\star \star * *$ & 1,41 & $\star * \star$ \\
\hline & Sentència & Separació de mutu acord & Ref. & & Ref. & & Ref. & \\
\hline & & Separació contenciosa & 0,70 & 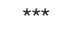 & 1,01 & & 1,73 & $\star \star \star \star$ \\
\hline & & Divorci consensuat & 0,98 & & 1,03 & & 0,94 & \\
\hline & & Divorci no consensuat & 0,60 & $\star \star * *$ & 1,17 & 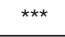 & 1,39 & 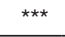 \\
\hline
\end{tabular}

Font: elaboració pròpia a partir de les microdades de les sentències proporcionades per l'INE.

Notes: Ref. = categoria de referència. En cursiva, la variable és significativa. Si la categoria és significativa: ${ }^{*} p<0,1,{ }^{* *} p<0,05,{ }^{* *} p<0,01$. Variables que es van analitzar anteriorment, però que es van excloure de l'anàlisi multivariada per la seva alta correlació $(>0,8)$ amb l'edat del marit en el matrimoni: l'edat de la dona en el matrimoni, l'edat del marit i de la dona en el moment de la sol-licitud de divorci i la sentència. La dada sobre la separació anterior (abans del divorci) en va ser exclosa, perquè aquesta característica només és possible en cas de divorci i, lògicament, no té lloc quan hi ha una separació. De la mateixa manera, les variables pensió compensatòria i pensió d'aliments no podrien ser comprovades, ja que el pagament depèn de qui obté la custòdia, i no a l'inrevés. En alguns casos, s'hi han agregat les categories de les variables amb pocs exemples o quan no s'hi han observat diferències estadístiques amb altres categories. 


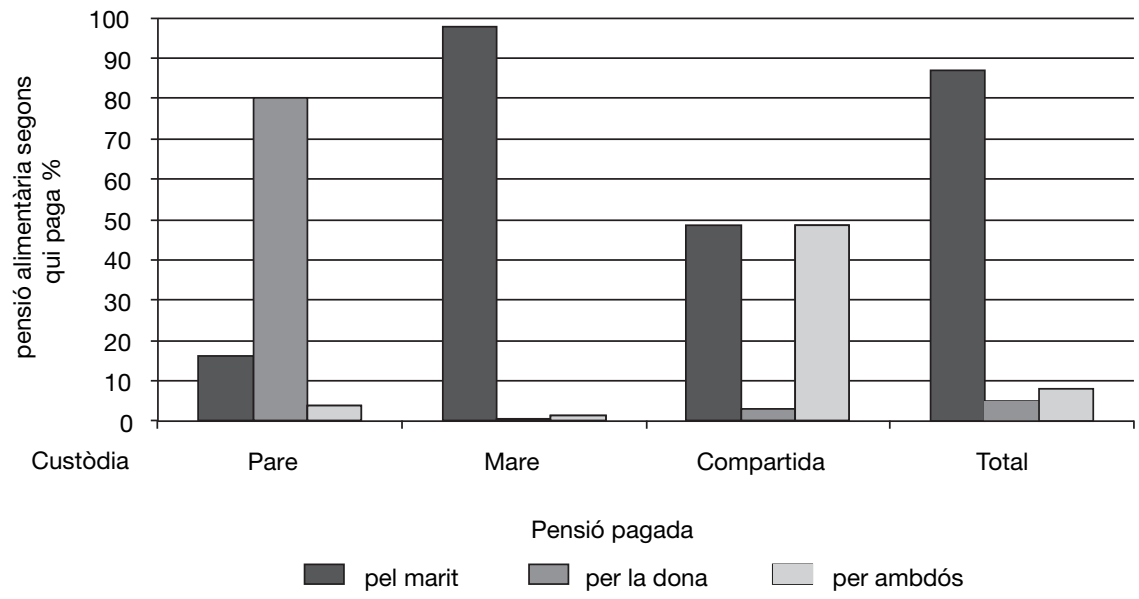

Figura 4. Pensió alimentària segons el tipus de custòdia (Catalunya 2007-2010).

Font: elaboració pròpia a partir de les microdades de les sentències proporcionades per l'INE.

de capital social, etc.) similars entre els cònjuges, però que són relativament més complicats quan les relacions de poder entre la parella són molt desiguals. La figura de la custòdia compartida conté i amaga acords ben diversos i crea escenaris molt complexos de la realitat del postdivorci.

\section{Reflexions finals}

Després d'introduir el debat obert sobre la custòdia compartida arran de la reforma de l'any 2005, en el present article, hi hem presentat evidències de l'especificitat de Catalunya en el context de l'Estat espanyol per al període 2007-2012 i, a continuació, hi hem analitzat amb més detall les característiques de la custòdia compartida a Catalunya durant un període més curt (20072010), que es troba a cavall entre la reforma espanyola de 2005 i l'entrada en vigor de la llei catalana, que va tenir lloc a principis de 2011.

En plena crisi econòmica, la incidència de les sentències en què es va establir la custòdia compartida dels fills menors es va més que doblar a Catalunya entre 2007 i 2012 (va passar del 12\% al 26\%), mentre que a la resta de l'Estat va passar del $9 \%$ al $12 \%$. En canvi, hi va haver una reducció del $23 \%$ en el nombre conjunt de divorcis i separacions, com també una reducció similar $(-19 \%)$ dels casos amb presència de fills menors.

\subsection{Per què augmenta la custòdia compartida a Catalunya?}

Per tal d'explicar l'augment tan notable de les sentències amb custòdia compartida en un lapse de temps tan curt (sis anys), la hipòtesi de considerar la 
custòdia compartida com a "opció preferent» per part dels jutges no sembla plausible, atès que una part important corresponen a sentencies consensuades (un $85 \%$ a 2012). Tanmateix, no es pot descartar del tot, sense conèixer més detalls respecte del $15 \%$ de les sentències contencioses, en les quals la decisió del jutge té el pes més elevat.

L'augment tampoc no es pot atribuir a un canvi sobtat de comportament dels rols parentals dins de la societat catalana, perquè sabem que, en aquest terreny, les transformacions són lentes $\mathrm{i}$, a vegades, reversibles, a part que el període estudiat és massa curt. Més aviat cal relacionar-lo amb una nova cultura i pràctica judicials basades en el reconeixement de models nous de coparentalitat en el predivorci. En aquest sentit, el grau més elevat d'autonomia econòmica de les dones i l'expressió de noves masculinitats en l'exercici de la paternitat desbanquen la guarda exclusiva dels infants per part de la mare (i el pare com a finançador en solitari de la pensió d'aliments) com a única fórmula en el postdivorci, la qual fou moneda corrent abans de la reforma de 2005.

D'altra banda, el divorci constitueix un punt d'inflexió en la biografia dels qui el viuen, que suposa reptes nous que requereixen la mobilització de tots els recursos (materials, simbòlics i relacionals), per tal d'ajustar-se a una situació no experimentada fins aleshores i desenvolupar un projecte vital desconegut del qual poden sorgir trajectòries familiars múltiples, en un marc de restriccions econòmiques i temporals diverses (Solsona et al., 2007; Solsona, 2009; GarciaPereiro i Solsona, 2011). En aquest sentit, i en un context de crisi econòmica profunda, la demanda creixent de custòdia compartida també pot respondre a la defensa d'interessos econòmics per part del pare, que, malgrat que no hagi practicat la criança compartida a la vida diària durant el matrimoni, en el moment de la ruptura s'escora cap a la custòdia compartida com a element de negociació per evitar pagar la pensió d'aliments o per obtenir-ne una de més reduïda.

En definitiva, la custòdia compartida pot ser un instrument legal per acordar orientacions dels progenitors comunes cap als fills, però no pas sobre la base d'unes pràctiques parentals equitatives en «temps» $\mathrm{i}$ «diners» dedicats als fills. En aquest sentit, en molts casos, pot ser un «miratge» pel que fa a representar una equitat social més elevada.

\subsection{La custòdia compartida: un "concepte en construcció» per significar unes pràctiques en construcció}

L'anomenada custòdia compartida dóna lloc a confusió entre el que seria la responsabilitat legal (potestat parental) i la responsabilitat (guarda) de la cura dels fills en la vida quotidiana (per exemple: Scott, 1992; Catalán Frías, 2011). En canvi, la distinció entre responsabilitat legal i responsabilitat en la vida quotidiana es fa més clarament en els països anglosaxons (joint physical custody; joint legal custody; shared custody). Altres veus consideren més adequat el terme de guarda alternativa o alternada, ja que els progenitors deixen de viure junts. 
Nosaltres considerem que, amb el temps i mitjançant l'observació de les pràctiques reals, caldrà afinar els conceptes jurídics segons la dimensió de la responsabilitat compartida que s'estigui dirimint. Si fem esment a la modalitat residencial dels fills i les filles després de la ruptura conjugal, probablement seria millor parlar de guarda compartida amb residència alternada. A Espanya, advocats i mediadors familiars estan proposant múltiples variants de residència alternada en els acords de custòdia compartida. A més, pel que es refereix a la custòdia individual, la casuística residencial dels fills i filles també pot ser molt variable segons quins siguin els períodes regulars de trobada amb el progenitor o la progenitora no custodi. Així doncs, per conèixer la dinàmica real de la custòdia compartida a Catalunya, cal començar a investigar quins són els usos residencials dels fills i les filles en el postdivorci, més enllà dels pactes escrits i de les sentències judicials. Només a partir d'una recerca qualitativa sobre l'observació de les pràctiques reals podrem afinar millor els conceptes.

En canvi, si pensem de manera específica en la dimensió de cura i educació dels infants i dels adolescents, és millor la idea de "guarda i educació compartida» que no pas alternada. El concepte sociològic de cura compartida es pot associar més facilment amb la idea legal de coresponsabilitat i coparentalitat, és a dir, amb els pactes que mare i pare han d'establir en el Pla de parentalitat respecte d'alguns criteris i d'algunes pràctiques educatives que es poden negociar i renegociar segons quina sigui l'etapa de creixement dels fills i les filles (Brullet et al., 2011). Des d'una visió realista, no és raonable esperar pràctiques i valors educatius idèntics per part de mare i de pare en el postdivorci, com tampoc no és raonable esperar-los en el comú de les unitats familiars biparentals actuals, perquè el procés d'individualització ha significat l'entrada a les llars (a ritmes i intensitats diferents) de la negociació i el pacte, no només en afers de parella, sinó també en les relacions d'aquesta amb els fills i les filles.

Per tant, estem construint conceptes per expressar fenòmens dinàmics $\mathrm{i}$ complexos que formen part de les transformacions familiars més recents al nostre país. Necessitem i cal donar nom a les noves pràctiques parentals emergents, no negar-les ni sobredimensionar-les, i tenir molt present que coexisteixen en velles maneres de fer i de pensar la família. D’aquí les dificultats per conèixer $i$ anomenar les realitats familiars en tota la seva complexitat i diversitat actual i fer justícia en un món de desigualtats.

\section{Referències bibliogràfiques}

Alascio, L. (2011). «La excepcionalidad de la custodia compartida impuesta (art. 92.8 CC): A propósito de la Sentència del Tribunal Supremo de 1 de octubre de 2010». InDret: Revista para el Análisis del Derecho, 2/2011.

Alascio, L. i Marín, I. (2007). "Juntos pero no revueltos: La custodia compartida en el nuevo art. 92 CC». InDret: Revista para el Análisis del Derecho, 3/2007.

Barea, C. (2012). Los inconvenientes de la custodia compartida. Milton Keynes, Regne Unit: Lightning Source. 
Beck, U. i Beck-Gernsheim, E. (2003). La individualización. Barcelona: Paidos.

Brullet, C. (1996). Anàlisi de l'organització i repartiment del treball familiar i el treball remunerat entre parelles joves amb criatures petites: Pràctiques, representacions $i$ condicions materials de vida [en línia]. Bellaterra: Universitat Autònoma de Barcelona. Tesi doctoral. <http://www.tesisenxarxa.net/TDX-0625109-164502/>.

- (1998). "Relacions de gènere i dinàmiques familiars a Catalunya». A: Giner, S. et al. La Societat Catalana. Barcelona: Generalitat de Catalunya. Institut Català d'Estadística, 443-465.

- (2007). "Cap a un sistema familiar postpatriarcal?». A: Bodelón, E. i GímÉnez, P. Construint els drets de les dones: Dels conceptes a les politiques locals. Barcelona: Diputació de Barcelona, 217-236. Col-lecció Estudis, sèrie Igualtat i Ciutadania, 1.

- (2008). "Vida quotidiana i cura dels altres: Afrontant el canvi i la complexitat familiar». A: Riquer, Borja de et al. (dir.). Història, política, societat i cultura dels Països Catalans. Volum 13. L'inici d'un nou mil.lenni, 1998-2007. Barcelona: Enciclopèdia Catalana.

- (2010). «Cambios familiares y nuevas políticas sociales en España y Cataluña: El cuidado de la vida cotidiana a lo largo del ciclo de vida». Educar [en línia], 45. Monográfic «Educación y Familia». UAB-Departament de Pedagogia Aplicada. <http://ddd.uab.cat/pub/educar/0211819Xn45p51.pdf>.

Brullet, C. i Roca, C. (2008). Tenir cura dels fills: Temps, estratègies, xarxes socials $i$ politiques de suport a la criança [en línia]. Informe complet de recerca. Barcelona: Institut d'Infancia i Món Urbà (CIIMU). $<$ http://www.ciimu.org/>.

Brullet, C.; Marí-Klose, M.; Marí-Klose, P. i Maranzana, L. (2011). "Geografías de la paternidad no residente: ¿¿Ausente o vinculado». Documents d'Anàlisi Geogràfica, 57 (1), 83-103.

Caprile, M.; Vallvé, C. i Moreno, D. (1998). «El mercat de treball a Catalunya». A: Giner, S. (dir.). La societat catalana. Barcelona: Institut d'Estadística de Catalunya.

Cardús, S. (1999). "Família i canvi social». A: Riquer, Borja de. Història, política, societat $i$ cultura dels Pä̈sos Catalans. Volum 12. Autogovern i reptes de la fi de segle 1980-1997. Barcelona: Enciclopèdia Catalana, 236-249.

Catalán Frías, M. J. (2011). "La custodia compartida». Derecho y Criminología. Anales, 1, 57-82.

Dowling, A. (2013). La reconstrucció nacional de Catalunya 1939-2012. Barcelona: Pasado \& Presente.

Escobedo, A. (2011). "The social politics of fatherhood in Spain and France: A comparative analysis of parental leave and shared residence». Ethnologie française [en línia], 42 (1), 117-126. <http://dx.doi.org/10.3917/ethn.121.0117>.

Folberg, J. (1991). Joint custody and shared parenting. Nova York: Guilford Press.

García-Pereiro, Thaís; Solsona, Montserrat (2011). «El divorcio como nudo biográfico: Una revisión de la literatura reciente desde la perspectiva de la vulnerabilidad postdivorcio». Documents d'Anàlisi Geogràfica. Monogràfic "Geografies de la infancia, la joventut i les famílies», 57 (1), 105-126.

Generalitat de Catalunya (2008). Dones i treball: Publicació estadística del Departament de Treball. Anuari 2007. Barcelona: Direcció General d'Igualtat d'Oportunitats en el Treball i Gabinet Tècnic del Departament de Treball de Catalunya. Generalitat de Catalunya. 
Gimeno, J. i Ortí, M. (2008). "Guarda i custòdia compartida: Criteris de decisió i problemàtica social». Jornada sobre problemes emergents entorn dels menors $i$ les famílies en l'àmbit civil. Generalitat de Catalunya. Departament de Justícia. Centre d'Estudis Jurídics i Formació Especialitzada. Document consultat en PowerPoint.

Graversen, J. (1986). "Denmark: Custody Reform». Journal of Family Law, 25, 8I-89.

Halla, M. (2009). "The Effect of Joint Custody on Marriage and Divorce». IZA Discussion Paper, 4314.

Homs, O. i Caprile, M. (2010). «L'impacte de la crisi en el mercat de treball». A: Subirats, M. (coord.). Societat Catalana 2010. Barcelona: Associació Catalana de Sociologia. Institut d'Estudis Catalans.

IDESCAT (Institut d'Estadística de Catalunya) (2007). Enquesta de Condicions de Vida i Hàbits de la població de 2006 [en línia]. Barcelona: IDESCAT. $<$ http://www.idescat.net>.

- (2009). «Catalunya / Europa. Indicadors comparatius 2000-2008». Dossiers Idescat [en línia], 3. Barcelona: IDESCAT. <http://www.idescat.cat/cat/idescat/publicacions/cataleg/pdfdocs/dossier03.pdf>.

- (2011). Enquesta de l'ús del temps 2010-2011. Avanç de resultats. Nota de premsa del 14 d'abril de 2011 [en línia]. <http://www.idescat.cat/cat/idescat/serveis/premsa/NPeut2010-2011a.pdf>.

Lathrop, F. (2009). «Custodia compartida y corresponsabilidad parental: Aproximaciones jurídicas i sociológicas». Diario La Ley, 7206 (1).

Marí-Klose, P.; Gómez-Granell, C.; Brullet, C. i Escapa, S. (2008). Temps de les famílies: Anàlisi sociològica dels usos del temps dins de les llars catalanes a partir de les dades del panel de Famílies i Infancia del CIIMU [en línia]. Barcelona: Generalitat de Catalunya. Departament d'Acció Social i Ciutadania. <http://www.gencat.cat/benestar/secretariafamilia/TempsFamilia.pdf>.

Molénat, X. (2006). L'individu contemporain. París: Sciences Humaines Éditions.

Moreno, S. (20I3). «Gènere: L'anàlisi de les transicions juvenils des de la perspectiva de gènere». A: Enquesta a la Joventut de Catalunya 2012. Barcelona: Generalitat de Catalunya. Departament de Benestar Social i Família. Estudis, 34.

Picontó, T. (ed.) (2012). La custodia compartida a debate. Madrid. Dykinson. Cuadernos Bartolomé de las Casas, 56.

Sanahuja, M. (2010). "La custodia compartida como modelo preferente». Estudios Jurídicos, 2010.

SAvolainen, M. (1986). "Finland: more rights for children». Journal of Family Law, 25, 113-126.

Scotт, E. S. (1992). «Pluralism, parental preference, and child custody». California Law Review [en línia], 80 (3), 615-672. $<$ http://dx.doi.org/10.2307/3480710>.

Solsona, M. (2009). "Narrar la propia biografía después de un divorcio. Notas de un estudio cualitativo de interés para la demografía». Estudios Geográficos, 70 (267), 633-660.

<http://dx.doi.org/10.3989/estgeogr.0467>

Solsona, M. i Ferrer, L. (2010). «(Re) Construcció de les maternitats i de les paternitats després d'un divorci: Notes d'un estudi qualitatiu». Treballs de la Societat Catalana de Geografia, 69, 141-166.

Solsona, M.; Ferrer, L.; Simó, C. i MacInnes, J. (2007). «Trayectorias familiares después del divorcio: Una revisión de las contribuciones recientes desde la demografía». Documents d'Anàlisi Geogràfica, 49, 217-234. 
Solsona, M. i Simó, C. (2007). «Evolución histórica del divorcio en España desde la aprobación de la ley de 1981 hasta la reforma de 2004». A: Cabré, A. i Miret, P. (eds.). La constitución familiar en España. Bilbao: Fundación BBVA, 245-296.

Spijker, J. (2012). "Trends in custody arrangements in Spain since the Divorce Reform of 2005». Papers de Demografia, 404.

Spruijt, E. i Duindam, V. (2009). "Joint physical custody in the Netherlands and the well-being of children». Journal of Divorce \& Remarriage [en línia], 51 (1), 65-82. <http://dx.doi.org/10.1080/10502550903423362>.

Sunstein, C. (1996). "The Expressive Function of Law». University of Pennsylvania Law Review [en línia], 144, 2021-2054. <http://dx.doi.org/10.2307/3312647>.

Théry, I. (1998). Couple, filiation et parenté aujourd'hui. París: Odile Jacob.

Torns, T.; Carrasquer, P.; Parella, S. i Recio, C. (2007). Les dones i el treball a Catalunya: Mites $i$ certeses. Barcelona: Generalitat de Catalunya. Institut Català de les Dones.

Torns, T.; Moreno, S.; Borràs, V. i Recio, C. (2008). "Ciutadania i benestar quotidià: Una relació imprescindible per a la societat del segle XXI». A: Montagut, M. (coord.). Societat Catalana 2008. Barcelona: Institut d'Estudis Catalans. Associació Catalana de Sociologia. 


\section{Annex A. Tipus de custòdia segons les característiques dels cònjuges, la} unió i el procés legal (Catalunya 2007-2010)

\begin{tabular}{|c|c|c|c|c|c|c|c|}
\hline \multirow[b]{2}{*}{ Factor } & \multirow[b]{2}{*}{ Variable } & \multirow[b]{2}{*}{ Categories } & \multicolumn{3}{|c|}{ Custòdia } & \multirow[b]{2}{*}{ Total $^{*}$} & \multirow[b]{2}{*}{$\mathrm{N}^{*}$} \\
\hline & & & Pare & Mare & Comp. & & \\
\hline \multirow[t]{24}{*}{ Cònjuges } & \multirow{5}{*}{$\begin{array}{l}\text { Edat del pare en el } \\
\text { moment de casar-se }\end{array}$} & $<25$ anys & 34,6 & 29,3 & 27,3 & 29,3 & 13.353 \\
\hline & & $25-30$ anys & 37,0 & 42,0 & 43,3 & 41,9 & 19.085 \\
\hline & & 30-35 anys & 16,0 & 17,8 & 18,1 & 17,7 & 8.077 \\
\hline & & $35+$ anys & 12,3 & 10,9 & 11,3 & 11,1 & 5.045 \\
\hline & & Total & 100,0 & 100,0 & 100,0 & 100,0 & 45.561 \\
\hline & \multirow{5}{*}{$\begin{array}{l}\text { Edat de la mare en el } \\
\text { moment de casar-se }\end{array}$} & $<25$ anys & 57,3 & 49,8 & 48,9 & 50,0 & 22.800 \\
\hline & & $25-30$ anys & 24,9 & 33,5 & 35,2 & 33,3 & 15.176 \\
\hline & & $30-35$ anys & 11,8 & 11,3 & 11,2 & 11,3 & 5.159 \\
\hline & & $35+$ anys & 6,0 & 5,4 & 4,7 & 5,3 & 2.426 \\
\hline & & Total & 100,0 & 100,0 & 100,0 & 100,0 & 45.561 \\
\hline & \multirow{7}{*}{$\begin{array}{l}\text { Edat del pare en el } \\
\text { moment de la sentència }\end{array}$} & $<30$ anys & 2,1 & 3,2 & 2,3 & 3,0 & 1.377 \\
\hline & & 30-34 anys & 9,6 & 12,9 & 11,2 & 12,5 & 5.685 \\
\hline & & $35-39$ anys & 17,2 & 24,3 & 24,6 & 24,0 & 10.916 \\
\hline & & $40-44$ anys & 26,8 & 27,8 & 28,7 & 27,9 & 12.692 \\
\hline & & $45-49$ anys & 25,0 & 19,8 & 20,9 & 20,2 & 9.218 \\
\hline & & $50+$ anys & 19,2 & 12,0 & 12,4 & 12,4 & 5.671 \\
\hline & & Total & 100,0 & 100,0 & 100,0 & 100,0 & 45.561 \\
\hline & \multirow{7}{*}{$\begin{array}{l}\text { Edat de la mare en el } \\
\text { moment de la sentència }\end{array}$} & $<30$ anys & 5,0 & 7,1 & 5,6 & 6,8 & 3.096 \\
\hline & & $30-34$ anys & 14,0 & 18,4 & 17,8 & 18,1 & 8.226 \\
\hline & & 35-39 anys & 24,7 & 28,6 & 29,0 & 28,4 & 12.961 \\
\hline & & 40-44 anys & 28,6 & 26,2 & 27,2 & 26,5 & 12.052 \\
\hline & & 45-49 anys & 18,9 & 14,4 & 14,9 & 14,7 & 6.691 \\
\hline & & $50+$ anys & 8,7 & 5,4 & 5,5 & 5,6 & 2.534 \\
\hline & & Total & 100,0 & 100,0 & 100,0 & 100,0 & 45.561 \\
\hline \multirow[t]{13}{*}{ Unió } & \multirow{4}{*}{$\begin{array}{l}\text { Diferència } \\
\text { d'edat entre } \\
\text { els cònjuges }\end{array}$} & Homogàmia & 34,7 & 39,6 & 41,1 & 39,5 & 18.016 \\
\hline & & Hipogàmia & 9,5 & 9,7 & 8,5 & 9,5 & 4.326 \\
\hline & & Hipergàmia & 55,8 & 50,7 & 50,3 & 51,0 & 23.218 \\
\hline & & Total & 100,0 & 100,0 & 100,0 & 100,0 & 45.561 \\
\hline & \multirow{4}{*}{$\begin{array}{l}\text { Nacionalitat dels } \\
\text { cònjuges }\end{array}$} & 2 espanyols & 89,2 & 88,7 & 92,3 & 89,2 & 41.033 \\
\hline & & 1 espanyol i 1 estranger & 5,8 & 5,5 & 4,3 & 5,3 & 2.448 \\
\hline & & 2 estrangers & 5,0 & 5,8 & 3,4 & 5,5 & 2.514 \\
\hline & & Total & 100,0 & 100,0 & 100,0 & 100,0 & 45.995 \\
\hline & \multirow[t]{5}{*}{ Durada del matrimoni } & $<5$ anys & 6,6 & 9,3 & 7,8 & 9,0 & 4.123 \\
\hline & & $5-10$ anys & 15,7 & 23,9 & 24,2 & 23,5 & 10.812 \\
\hline & & $10-20$ anys & 49,0 & 48,2 & 48,3 & 48,3 & 22.222 \\
\hline & & $20+$ anys & 28,8 & 18,6 & 19,6 & 19,3 & 8.868 \\
\hline & & Total & 100,0 & 100,0 & 100,0 & 100,0 & 46.025 \\
\hline
\end{tabular}




\begin{tabular}{|c|c|c|c|c|c|c|c|}
\hline \multirow[b]{2}{*}{ Factor } & \multirow[b]{2}{*}{ Variable } & \multirow[b]{2}{*}{ Categories } & \multicolumn{3}{|c|}{ Custòdia } & \multirow[b]{2}{*}{ Total* } & \multirow[b]{2}{*}{$\mathrm{N}^{\star}$} \\
\hline & & & Pare & Mare & Comp. & & \\
\hline \multirow[t]{10}{*}{ Unió } & \multirow{3}{*}{$\begin{array}{l}\text { Estat civil anterior } \\
\text { del marit }\end{array}$} & Solter & 94,0 & 94,3 & 94,9 & 91,1 & 42.679 \\
\hline & & Divorciat/vidu & 6,0 & 5,7 & 5,1 & 8,9 & 2.550 \\
\hline & & Total & 100,0 & 100,0 & 100,0 & 100,0 & 45.229 \\
\hline & \multirow{3}{*}{$\begin{array}{l}\text { Estat civil anterior } \\
\text { de la dona }\end{array}$} & Soltera & 93,8 & 95,8 & 96,2 & 92,9 & 43.295 \\
\hline & & Divorciada/vídua & 6,2 & 4,2 & 3,8 & 7,1 & 1.934 \\
\hline & & Total & 100,0 & 100,0 & 100,0 & 100,0 & 45.229 \\
\hline & Fills menors & 1 & 53,8 & 69,1 & 76,2 & 69,2 & 26.210 \\
\hline & \multirow[t]{3}{*}{ d'edat } & 2 & 31,3 & 21,1 & 16,8 & 21,1 & 17.393 \\
\hline & & $3+$ & 14,9 & 9,8 & 7,0 & 9,7 & 2.423 \\
\hline & & Total & 100,0 & 100,0 & 100,0 & 100,0 & 46.026 \\
\hline \multirow{22}{*}{$\begin{array}{l}\text { Procés } \\
\text { judicial }\end{array}$} & \multirow[t]{4}{*}{ Demandant } & Marit & 39,9 & 18,5 & 19,0 & 19,6 & 9.042 \\
\hline & & Dona & 26,6 & 35,7 & 22,4 & 33,4 & 15.373 \\
\hline & & Tots dos & 33,5 & 45,9 & 58,6 & 47,0 & 21.613 \\
\hline & & Total & 100,0 & 100,0 & 100,0 & 100,0 & 46.028 \\
\hline & \multirow[t]{4}{*}{ Durada del procés } & $<6$ mesos & 53,8 & 69,1 & 76,2 & 69,2 & 31.840 \\
\hline & & 6-11 mesos & 31,3 & 21,1 & 16,8 & 21,1 & 9.709 \\
\hline & & $12+$ mesos & 14,9 & 9,8 & 7,0 & 9,7 & 4.478 \\
\hline & & Total & 100,0 & 100,0 & 100,0 & 100,0 & 46.027 \\
\hline & \multirow[t]{6}{*}{ Sentència } & Separació de mutu acord & 4,8 & 5,9 & 7,1 & 6,0 & 2.753 \\
\hline & & Separació contenciosa & 3,2 & 2,2 & 1,4 & 2,1 & 964 \\
\hline & & Divorci consensuat & 51,6 & 65,3 & 75,6 & 65,9 & 30.336 \\
\hline & & Divorci no consensuat & 40,3 & 26,6 & 16,0 & 26,0 & 11.951 \\
\hline & & Nul.litat matrimonial & 0,1 & 0,1 & 0,0 & 0,1 & 24 \\
\hline & & Total & 100,0 & 100,0 & 100,0 & 100,0 & 46.028 \\
\hline & \multirow[t]{4}{*}{ Pensió compensatòria } & Marit & 5,7 & 10,7 & 13,0 & 10,7 & 4.935 \\
\hline & & Dona & 7,6 & 0,3 & 1,2 & 0,8 & 374 \\
\hline & & No consta & 86,7 & 89,0 & 85,8 & 88,5 & 40.716 \\
\hline & & Total & 100,0 & 100,0 & 100,0 & 100,0 & 46.025 \\
\hline & \multirow[t]{4}{*}{ Pensió d'aliments } & Marit & 16,3 & 97,9 & 48,6 & 86,8 & 39.952 \\
\hline & & Dona & 79,9 & 0,6 & 2,9 & 5,0 & 2.289 \\
\hline & & Tots dos & 3,7 & 1,4 & 48,5 & 8,2 & 3.762 \\
\hline & & Total & 100,0 & 100,0 & 100,0 & 100,0 & 46.026 \\
\hline Total & & $\mathrm{N}$ & 2.330 & 37.196 & 6.330 & & $46.026^{\star}$ \\
\hline
\end{tabular}

Font: elaboració pròpia a partir de les microdades de les sentències proporcionades per l'INE.

Notes: *La columna del total inclou quan s'ha concedit la custòdia a unes altres persones (170). Les diferències entre els totals també són fruit de la falta d'informació sobre algunes característiques referents a alguns individus (per exemple: en el cas de 466 persones no se sabia l'edat dels cònjuges en el moment de casar-se). 
Annex B. Característiques dels cònjuges, la unió i el procés legal segons el tipus de custòdia (Catalunya 2007-2010)

\begin{tabular}{|c|c|c|c|c|c|c|c|}
\hline \multirow[b]{2}{*}{ Factor } & \multirow[b]{2}{*}{ Variable } & \multirow[b]{2}{*}{ Categories } & \multicolumn{3}{|c|}{ Custòdia } & \multirow[b]{2}{*}{ Total } & \multirow[b]{2}{*}{$\mathrm{N}$} \\
\hline & & & Pare & Mare & Comp. & & \\
\hline \multirow[t]{20}{*}{ Cònjuges } & \multirow{4}{*}{$\begin{array}{l}\text { Edat del pare en el } \\
\text { moment de casar-se }\end{array}$} & $<25$ anys & 6,0 & 81,1 & 12,9 & 100,0 & 13.299 \\
\hline & & $25-30$ anys & 4,5 & 81,3 & 14,3 & 100,0 & 19.018 \\
\hline & & $30-35$ anys & 4,6 & 81,4 & 14,1 & 100,0 & 8.059 \\
\hline & & $35+$ anys & 5,7 & 80,2 & 14,2 & 100,0 & 5.015 \\
\hline & \multirow{4}{*}{$\begin{array}{l}\text { Edat de la mare en el } \\
\text { moment de casar-se }\end{array}$} & $<25$ anys & 5,8 & 80,7 & 13,5 & 100,0 & 22.702 \\
\hline & & $25-30$ anys & 3,8 & 81,6 & 14,6 & 100,0 & 15.120 \\
\hline & & 30-35 anys & 5,3 & 81,1 & 13,6 & 100,0 & 5.152 \\
\hline & & $35+$ anys & 5,7 & 82,0 & 12,3 & 100,0 & 2.417 \\
\hline & \multirow{6}{*}{$\begin{array}{l}\text { Edat del pare en el } \\
\text { moment de la sentència }\end{array}$} & $<30$ anys & 3,5 & 86,2 & 10,3 & 100,0 & 1.377 \\
\hline & & $30-34$ anys & 3,9 & 83,7 & 12,4 & 100,0 & 5.667 \\
\hline & & $35-39$ anys & 3,6 & 82,2 & 14,1 & 100,0 & 10.891 \\
\hline & & 40-44 anys & 4,9 & 80,9 & 14,2 & 100,0 & 12.636 \\
\hline & & 45-49 anys & 6,3 & 79,5 & 14,3 & 100,0 & 9.178 \\
\hline & & $50+$ anys & 7,9 & 78,4 & 13,8 & 100,0 & 5.641 \\
\hline & \multirow{6}{*}{$\begin{array}{l}\text { Edat de la mare en el } \\
\text { moment de la sentència }\end{array}$} & $<30$ anys & 3,8 & 84,9 & 11,3 & 100,0 & 3.086 \\
\hline & & $30-34$ anys & 3,9 & 82,4 & 13,6 & 100,0 & 8.199 \\
\hline & & $35-39$ anys & 4,4 & 81,5 & 14,1 & 100,0 & 12.917 \\
\hline & & 40-44 anys & 5,5 & 80,3 & 14,2 & 100,0 & 12.004 \\
\hline & & $45-49$ anys & 6,5 & 79,4 & 14,0 & 100,0 & 6.661 \\
\hline & & $50+$ anys & 8,0 & 78,4 & 13,6 & 100,0 & 2.524 \\
\hline \multirow[t]{17}{*}{ Unió } & \multirow{3}{*}{$\begin{array}{l}\text { Diferència } \\
\text { d'edat entre } \\
\text { els cònjuges }\end{array}$} & Homogàmia & 4,4 & 81,2 & 14,4 & 100,0 & 17.956 \\
\hline & & Hipogàmia & 5,1 & 82,5 & 12,4 & 100,0 & 4.316 \\
\hline & & Hipergàmia & 5,6 & 80,8 & 13,6 & 100,0 & 23.120 \\
\hline & \multirow{3}{*}{$\begin{array}{l}\text { Nacionalitat } \\
\text { dels conjuges }\end{array}$} & 2 espanyols & 5,1 & 80,6 & 14,3 & 100,0 & 40.882 \\
\hline & & 1 esp. i un estranger & 5,6 & 83,4 & 11,0 & 100,0 & 2.444 \\
\hline & & 2 estrangers & 4,6 & 86,6 & 8,7 & 100,0 & 2.500 \\
\hline & \multirow[t]{4}{*}{ Durada del matrimoni } & $<5$ anys & 3,7 & 84,3 & 12,0 & 100,0 & 4.114 \\
\hline & & 5-10 anys & 3,4 & 82,4 & 14,2 & 100,0 & 10.780 \\
\hline & & $10-20$ anys & 5,2 & 81,0 & 13,8 & 100,0 & 22.134 \\
\hline & & $20+$ anys & 7,6 & 78,3 & 14,1 & 100,0 & 8.827 \\
\hline & \multirow{2}{*}{$\begin{array}{l}\text { Estat civil anterior } \\
\text { del marit }\end{array}$} & Solter & 5,1 & 80,9 & 14,0 & 100,0 & 42.525 \\
\hline & & Divorciat/vidu & 5,4 & 82,1 & 12,5 & 100,0 & 2.535 \\
\hline & \multirow{2}{*}{$\begin{array}{l}\text { Estat. civil anterior } \\
\text { de la dona }\end{array}$} & Soltera & 5.0 & 81,0 & 14,0 & 100,0 & 43.138 \\
\hline & & Divorciada/vídua & 7.4 & 80,2 & 12,4 & 100,0 & 1.922 \\
\hline & \multirow{3}{*}{$\begin{array}{l}\text { Fills menors } \\
\text { d'edat }\end{array}$} & 1 & 5,6 & 81,5 & 13,0 & 100,0 & 26.146 \\
\hline & & 2 & 4,3 & 80,5 & 15,1 & 100,0 & 17.320 \\
\hline & & $3+$ & 5,4 & 81,3 & 13,3 & 100,0 & 2.390 \\
\hline
\end{tabular}




\begin{tabular}{|c|c|c|c|c|c|c|c|}
\hline \multirow[b]{2}{*}{ Factor } & \multirow[b]{2}{*}{ Variable } & \multirow[b]{2}{*}{ Categories } & \multicolumn{3}{|c|}{ Custòdia } & \multirow[b]{2}{*}{ Total } & \multirow[b]{2}{*}{$\mathrm{N}$} \\
\hline & & & Pare & Mare & Comp. & & \\
\hline \multirow{16}{*}{$\begin{array}{l}\text { Procés } \\
\text { judicial }\end{array}$} & \multirow[t]{4}{*}{ Demandant } & Marit & 10,3 & 76,3 & 13,4 & 100,0 & 8.995 \\
\hline & & Dona & 4,1 & 86,7 & 9,3 & 100,0 & 15.302 \\
\hline & & Tots dos & 3,6 & 79,2 & 17,2 & 100,0 & 21.562 \\
\hline & & $<6$ mesos & 3,9 & 80,9 & 15,2 & 100,0 & 31.767 \\
\hline & \multirow{2}{*}{$\begin{array}{l}\text { Durada } \\
\text { del procés }\end{array}$} & 6-11 mesos & 7,6 & 81,4 & 11,0 & 100,0 & 9.655 \\
\hline & & $12+$ mesos & 7,8 & 82,2 & 9,9 & 100,0 & 4.435 \\
\hline & \multirow[t]{4}{*}{ Sentència } & Separació de mutu acord & 4,0 & 79,7 & 16,3 & 100,0 & 2.747 \\
\hline & & Separació contenciosa & 7,7 & 83,2 & 9,1 & 100,0 & 961 \\
\hline & & Divorci consensuat & 4,0 & 80,2 & 15,8 & 100,0 & 30.265 \\
\hline & & Divorci no consensuat & 7,9 & 83,5 & 8,5 & 100,0 & 11.861 \\
\hline & \multirow{3}{*}{$\begin{array}{l}\text { Pensió } \\
\text { compensatòria }\end{array}$} & Marit & 2,7 & 80,6 & 16,7 & 100,0 & 4.929 \\
\hline & & Dona & 47,6 & 32,5 & 19,9 & 100,0 & 372 \\
\hline & & No consta & 5,0 & 81,6 & 13,4 & 100,0 & 40.555 \\
\hline & \multirow{3}{*}{$\begin{array}{l}\text { Pensió } \\
\text { d'aliments }\end{array}$} & Marit & 1,0 & 91,3 & 7,7 & 100,0 & 39.883 \\
\hline & & Dona & 81,6 & 10,4 & 8,1 & 100,0 & 2.283 \\
\hline & & Tots dos & 2,3 & 14,2 & 83,4 & 100,0 & 3.679 \\
\hline Total & & & 5,1 & 81,1 & 13,8 & 100,0 & 45.845 \\
\hline
\end{tabular}

Font: elaboració pròpia a partir de les microdades de les sentències proporcionades per l'INE. 